\title{
Modelled and measured effects of clouds on UV Aerosol Indices on a local, regional, and global scale
}

\author{
M. Penning de Vries and T. Wagner \\ Max Planck Institute for Chemistry, Mainz, Germany \\ Received: 9 July 2010 - Published in Atmos. Chem. Phys. Discuss.: 18 October 2010 \\ Revised: 30 September 2011 - Accepted: 2 December 2011 - Published: 16 December 2011
}

\begin{abstract}
The UV Aerosol Indices (UVAI) form one of very few available tools in satellite remote sensing that provide information on aerosol absorption. The UVAI are also quite insensitive to surface type and are determined in the presence of clouds - situations where most aerosol retrieval algorithms do not work. The UVAI are most sensitive to elevated layers of absorbing aerosols, such as mineral dust and smoke, but they can also be used to study non-absorbing aerosols, such as sulphate and secondary organic aerosols. Although UVAI are determined for cloud-contaminated pixels, clouds do affect the value of UVAI in several ways: (1) they shield the underlying scene (potentially containing aerosols) from view, (2) they enhance the apparent surface albedo of an elevated aerosol layer, and (3) clouds unpolluted by aerosols also yield non-zero UVAI, here referred to as "cloudUVAI".

The main purpose of this paper is to demonstrate that clouds can cause significant UVAI and that this cloudUVAI can be well modelled using simple assumptions on cloud properties. To this aim, we modelled cloudUVAI by using measured cloud optical parameters - either with low spatial resolution from SCIAMACHY, or high resolution from MERIS - as input. The modelled cloudUVAI were compared with UVAI determined from SCIAMACHY reflectances on different spatial (local, regional and global) and temporal scales (single measurement, daily means and seasonal means). The general dependencies of UVAI on cloud parameters were quite well reproduced, but several issues remain unclear: compared to the modelled cloudUVAI, measured UVAI show a bias, in particular for large cloud fractions. Also, the spread in measured UVAI is larger than in modelled cloudUVAI.

In addition to the original, Lambert Equivalent Reflector (LER)-based UVAI algorithm, we have also investigated
\end{abstract}

Correspondence to:

M. Penning de Vries

(marloes.penningdevries@mpic.de) the effects of clouds on UVAI determined using the socalled Modified LER (MLER) algorithm (currently applied to TOMS and OMI data). For medium-sized clouds the MLER algorithm performs better (UVAI are closer to 0), but like for LER UVAI, MLER UVAI can become as large as -1.2 for small clouds and deviate significantly from zero for cloud fractions near 1 . The effects of clouds should therefore also be taken into account when MLER UVAI data are used.

Because the effects of clouds and aerosols on UVAI are not independent, a simple subtraction of modelled cloudUVAI from measured UVAI does not yield a UVAI representative of a cloud-free scene when aerosols are present. We here propose a first, simple approach for the correction of cloud effects on UVAI. The method is shown to work reasonably well for small to medium-sized clouds located above aerosols.

\section{Introduction}

Aerosol particles are an important constituent of the atmosphere, as they perturb the distribution of solar radiation directly (by scattering and absorbing radiation) and indirectly (by affecting cloud properties), and influence atmospheric chemistry in a passive (as a catalyst or by providing a reaction surface) and active sense (e.g. Seinfeld and Pandis, 1998; Pöschl, 2005). The effects of an aerosol layer on its surroundings - properties of clouds, boundary layer and surface temperature - and hence on climate depend strongly on the absorptive properties of the aerosol particles (Andreae and Rosenfeld, 2008; Koren et al., 2008; Rosenfeld et al., 2008; Davidi et al., 2009). Despite the importance of information on aerosol absorption for accurate assessment of aerosol radiative effects, however, it is not well quantified on a global scale. The reason is that aerosol optical properties are difficult to determine by remote sensing.

Published by Copernicus Publications on behalf of the European Geosciences Union. 
The UV Aerosol Indices (UVAI), which are a measure of spectral contrast in the UV range, form a useful tool to study aerosol absorption: they are highly sensitive to aerosols that absorb UV radiation, they are relatively insensitive to surface type, and they are determined for cloudy as well as clear scenes. In the past, UVAI have mostly been applied to the study of UV-absorbing aerosols, such as mineral dust and smoke (e.g. Hsu et al., 1996, 2003; Herman et al., 1997; Gleason et al., 1998; Chiapello et al., 1999; Torres et al., 2002, 2005; Mahowald and Dufresne, 2004; Darmenova et al., 2005; Fromm et al., 2006; de Graaf et al., 2007). We have recently shown that aerosols that barely absorb UV radiation, here termed "scattering aerosols", can also be studied using UVAI, if its negative scale is regarded (Penning de Vries et al., 2009).

The quantitative interpretation of UVAI is not straightforward due to the strong dependence of UVAI on aerosol properties, in particular the layer altitude (ALH), aerosol optical thickness (AOT), and single-scattering albedo (SSA). One way to disentangle these influences is to take AOT and ALH from other satellite observations, as was recently shown in a paper by Jeong and Hsu, who presented a method to derive SSA of smoke particles by the combination of CALIOP ALH, MODIS AOT and OMI UVAI (Jeong and Hsu, 2008). Similar studies exploiting the strengths of different satellite instruments were presented recently, combining TOMS and MODIS (Hu et al., 2007), OMI and CALIOP (Dirksen et al., 2009; Guan et al., 2010), or MODIS and OMI (Satheesh et al., 2009). Alternatively, reflectances from a larger spectral window can be used in combination with UVAI to retrieve aerosol optical properties (Torres et al., 2007; Jethva and Torres, 2011; Veihelmann et al., 2007). In principle, the retrieval of AOT and SSA of scattering aerosols from UVAI is less complicated because UVAI is nearly independent of the altitude of a scattering aerosol layer (Penning de Vries et al., 2009). This advantage is partially negated by the reduced sensitivity of UVAI to scattering aerosols compared to absorbing aerosols.

Although difficult to use in a quantitative manner, UVAI are very suitable to indicate the presence of either UVabsorbing or non-absorbing aerosols without a priori input such as assumptions on size distribution or particle shape. The long time series of UVAI available, starting with the TOMS instruments in the late 1970s up to the currently active sensors SCIAMACHY, OMI and GOME-2 provides us with a unique and interesting dataset.

An important complicating issue in the way of quantitative application of the UVAI are the effects of clouds, particularly for satellite instruments with large footprints (e.g. SCIAMACHY, GOME-2, OMI), where completely cloud-free scenes are rare (Krijger et al., 2007). Clouds have various effects on UVAI: (1) when aerosols are present, clouds (partly) shield a lower-lying aerosol layer from view. Alternatively, (2) when a cloud is located below an aerosol layer it enhances the apparent surface albedo, which may increase the sensitiv- ity of UVAI to aerosol absorption due to multiple scattering between the cloud and the aerosol layer (Torres et al., 1998; Hsu et al., 1999, 2003; de Graaf et al., 2005). Much less known is the fact (3) that clouds also have an own contribution to UVAI (Penning de Vries et al., 2009). This contribution can be quite substantial: up to -1.5 units in magnitude. Because the cloud contribution to UVAI is negative, including cloud-contaminated pixels in temporal or spatial averages may lead to average UVAI values that are systematically too small.

The effects of clouds can be reduced by applying a cloud filter, but this means that a lot of (potentially very interesting) data are discarded. It also causes datasets to be biased to cloud-free scenes, and makes it impossible to study aerosolcloud interactions. Another way to deal with clouds is to model their effects on UVAI and use the results to correct the detected UVAI. For such a cloud-correction method to succeed, the dependence of UVAI from cloudy scenes on cloud parameters, aerosol parameters and measurement geometry needs to be known quite accurately.

The main objective of this paper is to demonstrate that UVAI from clouds unpolluted by aerosols (effect 3 above) can be well modelled with simple assumptions on cloud properties. For brevity, throughout this paper modelled UVAI from unpolluted clouds will be referred to as cloudUVAI, despite the fact that assigning an Aerosol Index to clouds is strictly not correct. We here present comparisons between modelled cloudUVAI from radiative transfer calculations with UVAI determined from SCIAMACHY data on different time scales (single measurement, daily and monthly averages) and different spatial scales (local, regional, and global).

Most of the paper is focussed on UVAI calculated using the Lambert-equivalent reflector (LER) algorithm, the method originally proposed by Herman and co-workers (Herman et al., 1997; Torres et al., 1998), which is currently used for the calculation of UVAI from GOME, SCIAMACHY, GOME-2, and OMI (http://www.temis.nl/ airpollution/absaai/). More briefly, we discuss the effects of clouds on the "modified" or "mixed" LER (MLER) UVAI algorithm, which is nominally applied to data from TOMS and OMI (O. Torres, personal communication, 2011).

Finally, we propose a first approach to a cloud-correction scheme for scenes where both aerosols and clouds are present, taking into account all three effects described above. The cloud-correction scheme was applied to three months of SCIAMACHY data.

\section{Method}

\subsection{UV Aerosol Indices}

The UVAI are a measure of the spectral contrast of a scene relative to the spectral contrast of a modelled scene where 
only Rayleigh scattering takes place (Herman et al., 1997; Torres et al., 1998). Because aerosol optical properties (scattering phase function, spectral dependences of optical thickness and absorption) differ from those of molecules, the presence of an aerosol layer causes a change in contrast between a wavelength $\lambda$ and a reference wavelength $\lambda_{0}$ in the UV range. The UVAI are calculated by modelling an atmosphere devoid of aerosols bounded by a Lambertian reflector with a certain albedo value. The albedo is chosen so that the modelled reflectance at $\lambda_{0}$ matches the measured reflectance at $\lambda_{0}$. The ratio between the measured and modelled reflectance at $\lambda$ then gives the UVAI (Torres et al., 1998):

$\mathrm{UVAI}=-100 \cdot{ }^{10} \log \left(\frac{R^{\text {meas }}}{R^{\text {Rayl }}}\right)_{\lambda}$

with $R^{\text {meas }}$ and $R^{\text {Rayl }}$ the measured and modelled reflectances at wavelength $\lambda$, respectively.

The positive part of UVAI is commonly defined as the Absorbing Aerosol Index (AAI); whereas the negative part is defined as the SCattering Index, or SCI (Penning de Vries et al., 2009):

$\mathrm{AAI}=\mathrm{UVAI}$ for UVAI $\geq 0$, undefined for UVAI $<0 \quad(2 \mathrm{a})$

$\mathrm{SCI}=\mathrm{UVAI}$ for UVAI $\leq 0$, undefined for UVAI $>0$

Our UVAI algorithm for SCIAMACHY was described in detail in (Penning de Vries et al., 2009), but will be explained shortly here. For each SCIAMACHY pixel, UVAI are determined from the measured reflectances at $\lambda=335.5 \mathrm{~nm}$ and $\lambda_{0}=376.5 \mathrm{~nm}$ by using a look-up-table (LUT). The LUT contains reflectances at $\lambda$ and $\lambda_{0}$ for all combinations of solar zenith angle (SZA) between 15 and $80^{\circ}$, line-of-sight zenith angle (LZA) from 0 to $35^{\circ}$, relative azimuth angle (RAZI) from 0 to $180^{\circ}$, and surface height from 0 to $7 \mathrm{~km}$, computed using the vector version of the SCIATRAN3.0 radiative transfer model (Rozanov et al., 2002, 2005). The LUT is interpolated to yield $R^{\text {Rayl }}$, which is then inserted into Eq. (1) to give the UVAI.

In a previous publication, we have estimated the error for our results from SCIAMACHY to be on the order of 0.20.3 UVAI units. Larger (systematic) errors may arise over surfaces with strong spectral dependence in the UV range (desert, "coloured" ocean regions), or due to strong altitude gradients within a satellite ground pixel. These issues were discussed in detail in (Penning de Vries et al., 2009) and will not be repeated here.

\subsection{Satellite instruments}

The SCanning Imaging Absorption spectroMeter for Atmospheric CHartographY (SCIAMACHY) and the MEdium Resolution Imaging Spectrometer (MERIS) are two of ten instruments that make up the payload of ESA's ENVISAT satellite. ENVISAT was launched in March 2002, into a descending polar orbit located at approximately $800 \mathrm{~km}$ from the Earth's surface. It passes the equator at a local time of 10:00 a.m.

SCIAMACHY is mainly used for the measurement of the gaseous composition of the Earth's atmosphere (Bovensmann et al., 1999; Wagner et al., 2008) by use of Differential Optical Absorption Spectroscopy (DOAS, Platt and Stutz, 2008). The instrument has a moderate spectral resolution, typically $0.2-0.4 \mathrm{~nm}$, but poor spatial resolution: generally, the ground pixel size is $30 \times 60 \mathrm{~km}^{2}$. SCIAMACHY's swath is $1000 \mathrm{~km}$ wide, and global coverage is achieved approximately every 6 days. The feature that makes SCIAMACHY unique are the alternating measurements in the limb and nadir modes, which allow collocated measurements of the total column of a trace gas (in nadir geometry) and its stratospheric profile (in limb geometry). The alternation of measurements in limb and nadir geometry is the reason for the division of the orbit into subsets of (generally) 260 measurements, called states.

The MERIS instrument was primarily developed to measure ocean colour (phytoplankton, coloured dissolved organic matter and suspended matter) over coasts and open ocean, clouds and water vapour concentrations in the atmosphere, and vegetation patterns over land (Bézy et al., 2000). MERIS detects Earth's reflectance in 15 programmable bands between 390 and $1040 \mathrm{~nm}$ with a spatial resolution of $1.04 \times 1.2 \mathrm{~km}^{2}$ over ocean. MERIS' swath is $1150 \mathrm{~km}$ wide, and global coverage is achieved every three days. For our investigations, we used the MERIS operational level-2 cloud optical thickness product, which was obtained from (http://merci-srv.eo.esa.int/merci/queryProducts.do).

\subsection{Radiative transfer modelling}

The radiative transfer modelling performed for this paper was done using the vector version discrete ordinate method (in plane-parallel atmosphere) implemented in SCIATRAN3.0 (downloaded from: http://www.iup.physik. uni-bremen.de/sciatran/downloads/), which is the successor to SCIATRAN2.0 (Rozanov et al., 2002, 2005).

For the modelling of clouds we used either phase functions and refractive indices from Mie calculations (Mie, 1908; van de Hulst, 1957), or phase functions and refractive indices representative of fractal ice particles (Macke et al., 1996). In both cases, clouds were assumed to be non-absorbing in the UV-visible wavelength range (SSA $=1.00)$. For the Mie calculations, Deirmendjians' gamma size distribution was used (A. Kokhanovsky, personal communication, 2010) (Deirmendjian, 1969) for cloud droplets with an effective radius, $r_{\text {eff }}=10 \mu \mathrm{m}$. Ice particles were assumed to be regular tetrahedrons with an edge length of $50 \mu \mathrm{m}$ (Rozanov and Kokhanovsky, 2006). Cloud optical thickness was assumed to be spectrally independent in all calculations, and surface albedo was set to 0.05 throughout the modelled wavelength range. Because UVAI are only moderately sensitive to the ozone column (Torres et al., 1998; de Graaf et al., 2005), an 
ozone profile typical of mid-latitude summer was used in all model calculations.

It should be noted here that our model results do not agree well with similar results published in Fig. 3 in (Torres et al., 2011). We calculated UVAI that are a factor of 2-3 larger in magnitude than those found by Torres and co-workers. To date, we have not been able to resolve this issue. We found, however, that our model results agree very well with those calculated using the newer version 3.1 of SCIATRAN (L. Lelli, personal communication, 2011). In addition, calculations using the DAK model are in excellent agreement with our results (M. de Graaf, personal communication, 2011). Since our results agree well with those from two independent researchers, we have some confidence in them. Nevertheless, work on resolving this important issue will continue.

To determine the cloud phase, we compared the cloud top height $(\mathrm{CTH})$ measured by SCIAMACHY with the altitude of the local $260 \mathrm{~K}$-isotherm. The altitude of the $260 \mathrm{~K}$ isotherm was read from a $2.8 \times 2.8^{\circ}$ monthly map of EMAC (ECHAM/MESSy Atmospheric Chemistry) (Jöckel et al., 2006) temperature profiles, sampled at the time of the satellite overpass. Clouds with top heights above the local $260 \mathrm{~K}$ isotherm were assumed to be in the ice phase; clouds at lower altitude were assumed to be liquid water clouds. For satellite pixels with effective cloud fractions too small for cloud top height retrieval by the HICRU algorithm $\left(\mathrm{CF}_{\text {eff }}<0.05\right)$ clouds were assumed to be warm (water) clouds.

\section{Theory}

\subsection{Cloud dependence of UV Aerosol Indices}

Clouds are complex three-dimensional structures that can be very inhomogeneous in their horizontal and vertical extent. Passive remote sensing satellite instruments such as SCIAMACHY and MERIS cannot resolve sub-pixel cloud structures, therefore their cloud detection algorithms typically retrieve averaged (or effective) cloud properties. Such algorithms make use of the increase in reflectance at the top of the atmosphere caused by the presence of clouds. The reflectance in the visible range is mostly determined by the fraction of the pixel covered by the cloud (geometrical cloud fraction, $\mathrm{CF}_{\text {geom }}$ ), and the cloud top albedo, which depends on cloud optical thickness (COT) in a non-linear fashion. If a satellite pixel is completely covered by clouds, if the clouds are assumed to be homogeneous throughout the satellite pixel, and if surface reflectivity is known, COT can be determined directly from the top-of-atmosphere reflectance. Due to the coarse spatial resolution of SCIAMACHY most pixels are only partially covered by clouds and usually only an effective cloud fraction $\left(\mathrm{CF}_{\text {eff }}\right)$ is determined. The $\mathrm{CF}_{\text {eff }}$ is a linear function of $\mathrm{CF}_{\text {geom }}$ and cloud albedo, and is well suited to account for the effects of clouds on trace gas retrievals (Wang et al., 2008). The definition of $\mathrm{CF}_{\text {eff }}$ in this paper is analogous to the definition of $\mathrm{CF}_{\text {eff }}$ in the FRESCO+ (Koelemeijer et al., 2001; Wang et al., 2008) and HICRU (Grzegorski et al., 2006) cloud retrieval algorithms:

$$
\mathrm{CF}_{\text {eff }}=\left(\frac{R^{\text {meas }}-R^{\text {clear }}}{R^{\text {cloudy }}-R^{\text {clear }}}\right)_{\lambda=758}
$$

where $R^{\text {meas }}$ is the measured (or modelled) reflectance at $758 \mathrm{~nm}, R^{\text {clear }}$ the reflectance under cloud- and aerosol-free conditions, and $R^{\text {cloud }}$ the reflectance of a pixel completely covered by a homogeneous cloud with a COT of 50 (equivalent to a reflective surface with albedo 0.80). A major shortcoming of $\mathrm{CF}_{\text {eff }}$ is that it cannot discriminate between optically thin and optically thick clouds: for example, a $\mathrm{CF}_{\text {eff }}$ of 0.5 can be due to clouds with a cloud albedo of 0.8 $(\mathrm{COT}=50)$ covering $50 \%$ of the pixel, by clouds with a cloud albedo of $0.4(\mathrm{COT}=10)$ covering the complete pixel, or anything in between.

The dependence of cloudUVAI (UVAI resulting from an unpolluted cloud) on $\mathrm{CF}_{\text {eff }}$ is determined by $\mathrm{COT}$ as well as $\mathrm{CF}_{\text {geom. }}$. Because those two quantities cannot be disentangled using the FRESCO+ or HICRU algorithms, we study two extreme cases: "thick clouds", which are clouds with $\mathrm{COT}=50$, but varying $\mathrm{CF}_{\text {geom }}$, of which the reflectances were calculated using the independent pixel approximation. And "thin clouds", which cover the entire ground pixel $\left(\mathrm{CF}_{\text {geom }}=1\right)$ and have varying COT.

In Penning de Vries et al. (2009) the modelled dependence of UVAI on $\mathrm{CF}_{\text {eff }}$ was shown for thick and for thin clouds, and it was found that the UVAI are nearly independent of cloud altitude (less than 0.1 units for nadir viewing geometry and overhead sun). The clouds were modelled using Henyey-Greenstein phase function parameterisation (Henyey and Greenstein, 1941), which does not accurately represent the true cloud phase functions (Hansen, 1969). We repeated the model study using more appropriate phase functions. The results are shown in Fig. 1a and b, for thick and thin clouds, respectively. These were obtained by modelling the clouds using phase functions from Mie calculations to represent warm water clouds (Mie clouds, dots and solid lines) or phase functions representative of ice particles (ice clouds, triangles and dotted lines) as described in Sect. 2.3. The results are shown for nadir viewing geometry and three different SZAs of 30,45 , and $60^{\circ}$. Warm clouds were modelled as plane-parallel layers with a geometrical thickness of $1 \mathrm{~km}$, starting at the surface, whereas ice clouds were located at $9-10 \mathrm{~km}$ altitude. For better comparison between panels $\mathrm{A}$ and $\mathrm{B}$, a second $\mathrm{x}$-axis is shown with $\mathrm{CF}_{\mathrm{eff}}$, which is equal to $\mathrm{CF}_{\text {geom }}$ for thick clouds (panel $\mathrm{A}$ ), and is determined from the modelled reflectance at $758 \mathrm{~nm}$ according to Eq. (3) for all thin clouds (panel B). In Figs. 1 and 3, $\mathrm{CF}_{\text {eff }}$ is only shown for the Mie cloud at $\mathrm{SZA}=30^{\circ}$; for ice clouds $\mathrm{CF}_{\text {eff }}$ can be up to a factor of 2 larger for COT $<10$. By definition, UVAI at $\mathrm{CF}_{\text {eff }}=0$ and $\mathrm{CF}_{\text {eff }}=1$, respectively, are identical for thick and thin clouds. 

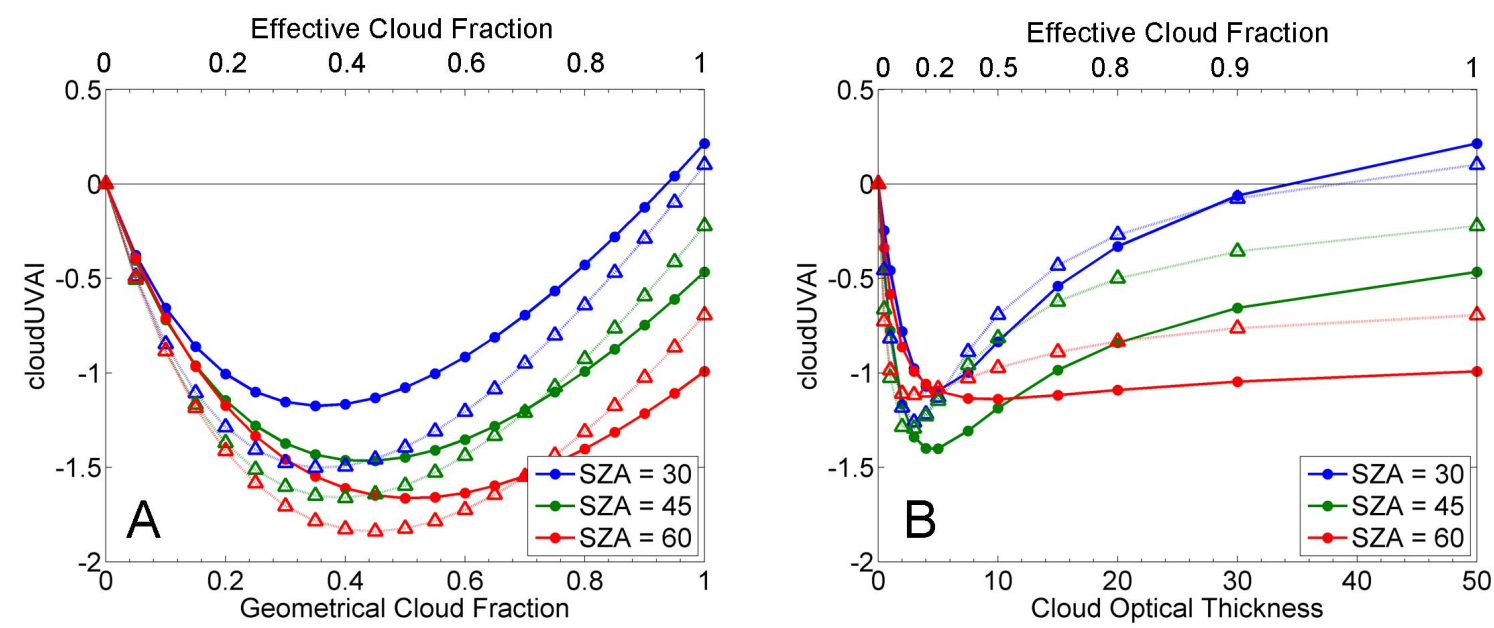

Fig. 1. cloudUVAI from RTM calculations. Clouds were modelled using Mie (dots, solid lines) or ice (triangles, dotted lines) phase functions. Albedo of the underlying surface was set to 0.05 . Viewing geometry is nadir and three solar zenith angles were modelled, as indicated in the figure legend. (A) Thick clouds (clouds with constant optical thickness of 50); (B) thin clouds (clouds with constant geometrical cloud fraction of 1) (see the text for details).
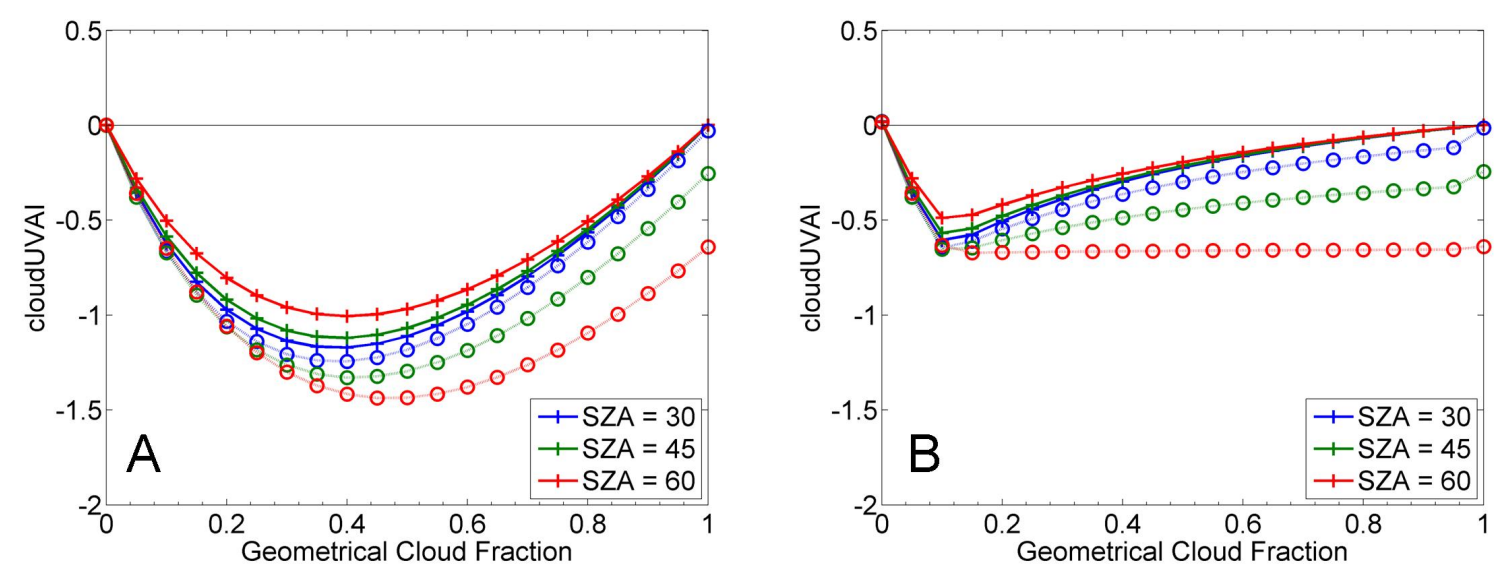

Fig. 2. cloudUVAI from RTM calculations. The clouds are modelled as Lambertian reflectors (crosses, solid lines) with albedo $=0.80$, located at an altitude of $1 \mathrm{~km}$, or using Henyey-Greenstein phase function parameterization with $g=0.87$ (circles, dotted lines). Albedo of the underlying surface was set to 0.05 . Viewing geometry is nadir and three solar zenith angles were modelled, as indicated in the figure legend. (A) UVAI calculated using LER algorithm; (B) UVAI calculated using MLER algorithm (see text).

As seen in Fig. 1, when $\mathrm{CF}_{\text {eff }}$ is higher than approximately 0.7 the cloud type (thick or thin) is not of great importance to UVAI: cloudUVAI are very similar in both panels for clouds with large $\mathrm{CF}_{\text {eff. }}$. For smaller $\mathrm{CF}_{\text {eff }}$, however, there can be a difference of up to 0.5 UVAI unit (in particular for large SZA) between the thick and thin cloud models. The cloudUVAI calculated for thick Mie and ice clouds are very similar, although ice clouds reach lower UVAI $(-1.8)$ than Mie clouds $(-1.6)$ at $\mathrm{SZA}=60^{\circ}$. For thin clouds, the situation is different: here, Mie and ice clouds are similar for all SZA, but the Mie cloud shows lower UVAI for SZA $=60^{\circ}$ and appears to have a broader peak. The latter effect becomes much smaller when each cloudUVAI curve is plotted against the $\mathrm{CF}_{\text {eff }}$ scale corresponding to the cloud type (water or ice) and
SZA. Due to the large differences in phase functions for the two parameterisations the angular dependences of cloudUVAI for Mie clouds and ice clouds are significantly different. This will be explored in more detail in Sect. 3.3.

Figure 2a displays cloudUVAI obtained when the cloud is modelled as a Lambertian surface with albedo equal to 0.80 (pluses and solid lines) or using Henyey-Greenstein (HG) phase function parameterisation (circles and dotted lines). The HG cloud has an asymmetry parameter $g=0.87$, a value considered appropriate for water clouds (Wendisch et al., 2005), and COT $=50$. The Lambertian and HG clouds were modelled using the independent pixel approximation, in analogy to the thick Mie and ice clouds. To improve the comparison with Fig. 1a, the Lambertian cloud was set to an 
altitude of $1 \mathrm{~km}$, although this changed the UVAI values by less than 0.05 units with respect to a Lambertian reflector at $0 \mathrm{~km}$ altitude. It is interesting to note here that a pixel with highly heterogeneous surface albedo in the UV range, e.g. an ocean pixel partially covered by ice, may, under certain viewing angles, yield a UVAI value very similar to an ocean pixel partially covered by a cloud.

The differences between the cloud models - the HG, Mie, and ice clouds on the one hand, and the Lambertian cloud on the other hand - are worth discussing in more detail. For small SZA, the differences are rather small, but for $\mathrm{SZA}=60^{\circ}$ the deviation between the $\mathrm{HG}$, Mie, and ice clouds and the Lambertian cloud increases; even the direction of the change in cloudUVAI with increasing SZA is different: for the Lambertian cloud, cloudUVAI increases slightly with SZA, whereas for the thick HG, Mie, and ice clouds, cloudUVAI decreases. Another striking difference is that cloudUVAI for Lambertian clouds with $\mathrm{CF}_{\text {eff }}=1$ is equal to 0 , whereas for the HG cloud and the more realistically modelled Mie and ice clouds with $\mathrm{CF}_{\text {eff }}=1$, cloudUVAI deviates strongly from 0 for $\mathrm{SZA}>30^{\circ}$. The reason for these differences is the angular dependence of the light scattered by the model cloud: whereas scattering by the Lambertian cloud is isotropic by definition, the asymmetric HG, Mie, and ice phase functions lead to anisotropic bi-directional reflectance functions (BRDFs) for these clouds.

\subsection{The Modified-LER approach}

In the previous section it was seen that the LER model used to calculate reflectances for the calculation of UVAI according to the original definition (Herman et al., 1997; Torres et al., 1998) introduces artefacts in the presence of clouds. In Ahmad et al. (2004) it was shown that for many cases, the socalled Modified-LER (MLER) model is sufficient to describe the effects of clouds. The MLER model differs from the LER model in that the scene reflectance is not determined by a single Lambertian reflector (with variable albedo value), but by the linear combination of two Lambertian reflectors: one representing the surface (with a fixed, small albedo value, e.g. 0.15) and one representing a cloud (with a fixed, large albedo value, e.g. 0.80). Accordingly, the TOMS Aerosol Index algorithm was updated by replacing the LER model with the MLER model for scenes where the reflectance measured at the reference wavelength $\lambda_{0}$ exceeds the reflectance calculated for a surface with an albedo of 0.15 (McPeters et al., 1998) (O. Torres, personal communication, 2011).

To compare the effects of clouds on the two algorithms, we modified our UVAI algorithm to resemble the MLER approach described above. The UVAI is still defined as given in Eq. (1), but for highly reflective scenes (corresponding to a surface albedo between 0.15 and 0.80$) R^{\text {Rayl }}$ is determined by a linear combination of reflectances calculated for albedo values of 0.15 and 0.80 . For scenes with very high reflectivity (corresponding to a surface albedo $>0.80$ ) the MLER algorithm is again identical to the LER algorithm. Because the Lambertian cloud, presented in the previous section, is defined in a similar same way (i.e. according to Eq. 3), applying the MLER UVAI algorithm to this cloud yields very small UVAI (Fig. 2b). The remaining deviations from 0 arise because the albedo of the part of the pixel representing the surface was 0.05 for the Lambertian cloud, whereas in the MLER algorithm the "dark" surface albedo is 0.15 .

For more realistic clouds modelled using Mie or ice phase functions the effect of clouds on MLER UVAI is larger than for Lambertian or HG clouds, as shown in Fig. 3. Whereas the effects of clouds on MLER UVAI are clearly diminished in comparison with the effects on LER UVAI for medium $\mathrm{CF}_{\text {eff }}$ (compare Figs. 1 and 3), clouds with $\mathrm{CF}_{\text {eff }}$ between 0.2 and 0.8 still have significant cloudUVAI (on the order of 1 UVAI unit for $\mathrm{SZA}=60^{\circ}$ ). Since the MLER and LER UVAI algorithms are identical for large cloud fractions, nonzero values of cloudUVAI are also found for HG and Mie clouds with $\mathrm{CF}_{\text {eff }}=1$ using the MLER algorithm. As mentioned above, the deviation from 0 is caused by the angular dependence of the light scattered by the model cloud.

\subsection{Sensitivity studies of cloudUVAI}

We extended the model study to investigate the dependence of cloudUVAI on the instrument viewing angle and cloud parameters in more detail. Throughout this sensitivity study, UVAI was calculated using the LER algorithm.

The viewing angle dependence of cloudUVAI is quite significant. This is illustrated in Fig. 4 for medium-sized clouds $\left(\mathrm{CF}_{\text {eff }}=0.4 ; \mathrm{CF}_{\text {geom }}=0.4\right.$ for the thick cloud; $\mathrm{COT}=10$ for the thin cloud) with a cloud top height of $1 \mathrm{~km}$ (water clouds) or $10 \mathrm{~km}$ (ice clouds). The cloudUVAI are plotted against the instrument's viewing angle, with positive values denoting a viewing direction towards the sun (RAZI $=40^{\circ}$, or eastern pixels in SCIAMACHY's case) and negative values having a RAZI $=140^{\circ}$. In Fig. 4a, cloudUVAI for thick (blue) and thin (green) Mie clouds (solid lines and dots) and ice clouds (dotted lines and triangles) with an effective cloud fraction of 0.4 and SZA $=30^{\circ}$ are shown; Fig. $4 \mathrm{~b}$ shows cloudUVAI for the Mie and ice clouds for SZA $=60^{\circ}$.

The viewing angle dependence is most pronounced for thin clouds and increases with increasing SZA. The largest effects are seen for the positive viewing angles, nominally on the eastern part of SCIAMACHY's swath, and imply an intrinsic East-West bias of cloudUVAI. The trend in viewing angle dependence is similar for Mie and ice clouds; the most prominent difference between Mie and ice clouds is the appearance of the cloud bow around a scattering angle of $140^{\circ}$ (e.g. at a viewing angle of $+10^{\circ}$ for $\mathrm{SZA}=30^{\circ}$ ).

In addition to the viewing angle dependence, we also tested the dependence of cloudUVAI on the effective droplet size $\left(r_{\text {eff }}\right)$ used in the Mie calculations. For this, we performed model calculations with $r_{\text {eff }}=4,8$ and $16 \mu \mathrm{m}$ (not shown). The difference in cloudUVAI was generally found 

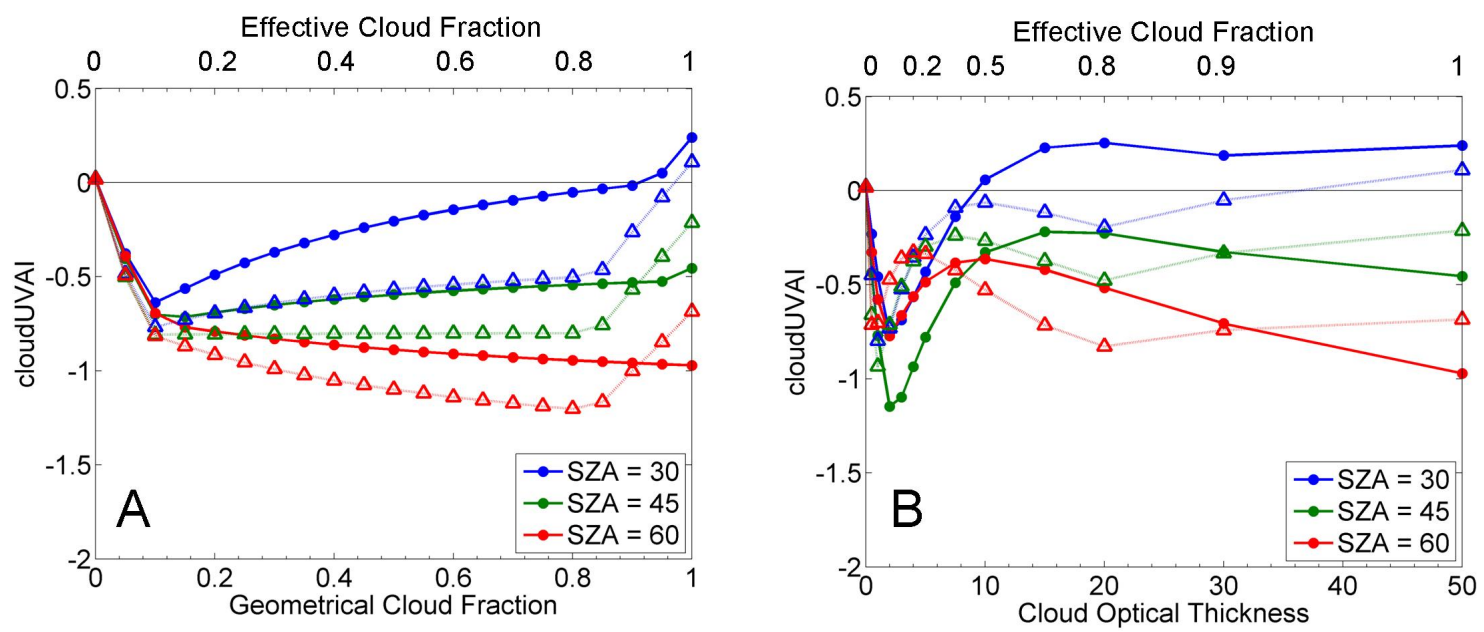

Fig. 3. MLER UVAI from RTM calculations. Clouds were modelled using Mie (dots, solid lines) or ice (triangles, dotted lines) phase functions, as in Fig. 1. Viewing geometry is nadir and three solar zenith angles were modelled, as indicated in the figure legend. (A) Thick clouds (clouds with constant optical thickness of 50); (B) thin clouds (clouds with constant geometrical cloud fraction of 1) (see the text for details).
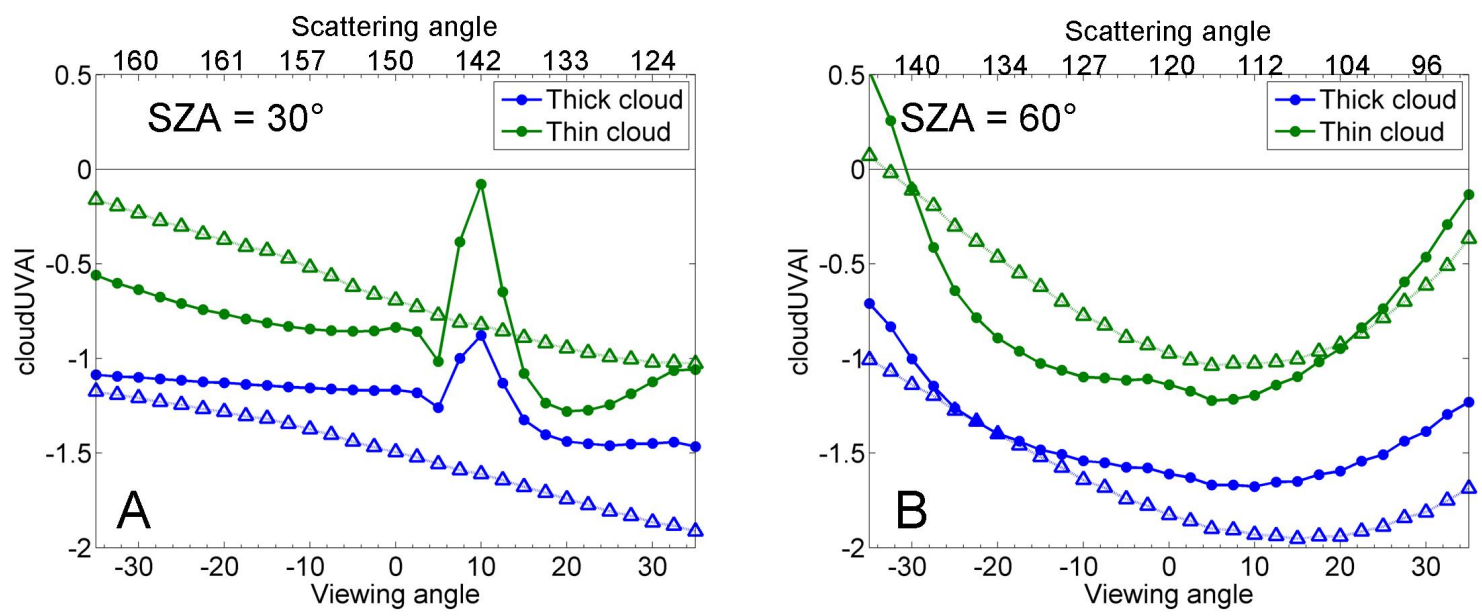

Fig. 4. Dependence of modelled cloudUVAI on viewing geometry. Cloud parameters for Mie clouds (solid lines and dots) and ice clouds (dotted lines and triangles) are given in the text. Thick clouds (blue) have a geometrical cloud fraction of $0.4(\mathrm{COT}=50)$; thin clouds (green) have an optical thickness of 10 (cloud fraction $=1$ ). Results are depicted for two solar zenith angles: $30^{\circ}(\mathbf{A})$ and $60^{\circ}(\mathbf{B})$. Positive viewing angles denote viewing direction towards the sun (RAZI $=40^{\circ}$; for nominal SCIAMACHY measurements, pixels in the east of the swath), negative viewing angles have $\mathrm{RAZI}=140^{\circ}$. The scattering angle is given in the second $\mathrm{x}$-axis at the top of the panels

to be small. However, due to the strong viewing angle dependence of cloudUVAI (especially for thin clouds, see Fig. 4), for certain viewing geometries cloudUVAI differences between droplets of 4 and $16 \mu \mathrm{m}$ can be as large as 0.5 units. For simplicity, and for lack of information on cloud particle size, we chose to use a fixed $r_{\text {eff }}$ of $10 \mu \mathrm{m}$ (also assumed in ISCCP, http://isccp.giss.nasa.gov) for all our model calculations.

We have also tested the sensitivity of cloudUVAI to the geometrical thickness of clouds, by calculating cloudUVAI for clouds with vertical extents ranging from 0.1 to $1 \mathrm{~km}$. For a thin cloud with COT $=10$, the change in cloudUVAI is less than $1 \%$ and can be neglected. Also, as long as the total COT is kept constant, the presence of more than one cloud layer has a negligible influence on cloudUVAI (less than $1 \%$ ).

In the UVAI wavelength range (around 335.5 and around $376.5 \mathrm{~nm}$ ) the Ring effect, the filling-in of Fraunhofer lines due to rotational Raman scattering (Grainger and Ring, 1962), can be quite pronounced. We investigated the influence of the Ring effect on UVAI by modelling cloudUVAI for clouds at various altitudes, either including rotational Raman scattering or not. We found that the difference in cloudUVAI did not exceed 0.5 units, even in viewing geometries that are extreme for SCIAMACHY. 


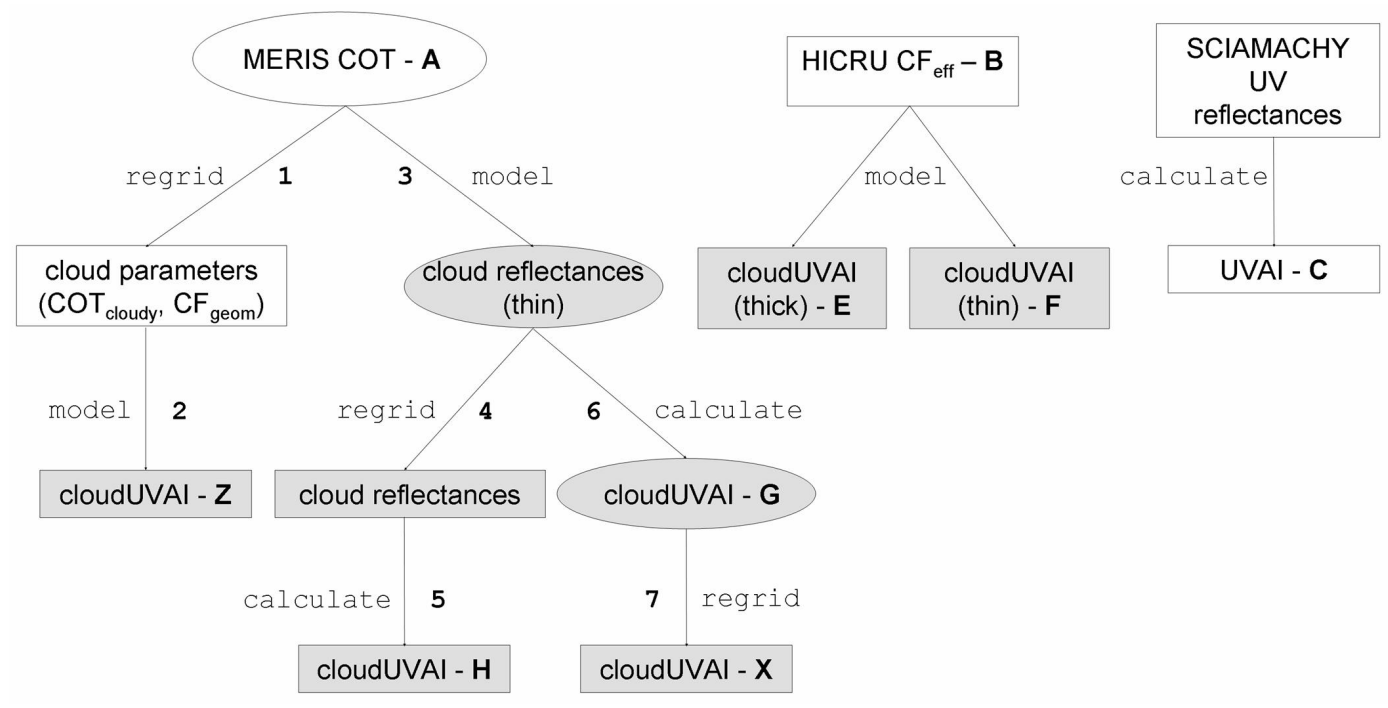

Fig. 5. Flow chart of the calculation of cloudUVAI from MERIS and SCIAMACHY cloud parameters. Rectangles symbolize quantities with SCIAMACHY spatial resolution $\left(30 \times 60 \mathrm{~km}^{2}\right)$, whereas ovals indicate MERIS spatial resolution $\left(1 \times 1 \mathrm{~km}^{2}\right)$. White boxes represent measured values; grey boxes show quantities which were derived from modelled clouds. Capital letters A to $\mathrm{H}$ (in bold font) refer to the data in corresponding panels in Figs. 6 and 7; the cloudUVAI data from the boxes marked "X" and " $Z$ " are mentioned in the text in Sects. 3 and 6 , but are not presented in this paper. The individual steps (labelled with "calculate", "model" and "regrid") are explained in the text.

\subsection{Calculation of cloudUVAI from satellite cloud data}

We have calculated cloudUVAI from HICRU effective cloud fractions for SCIAMACHY data from January to March 2005. For this, we created four separate look-up-tables (LUTs): two each for liquid water and ice clouds, respectively: one of the LUTs contains cloudUVAI for thick clouds with geometrical cloud fractions between 0 and 1 (and COT $=50$ ), and the other for thin clouds with cloud optical thickness between 0 and 50 (and $\mathrm{CF}_{\text {geom }}=1$ ). The (warm) water clouds were modelled using Mie phase function parameterisation for droplets with $r_{\text {eff }}=10 \mu \mathrm{m}$; ice clouds were modelled using phase functions representative of ice particles with $r=50 \mu \mathrm{m}$, as described in Sect. 2.3. The LUTs of cloudUVAI contain all combinations of viewing angles and solar zenith angles relevant for this study (SZA 15$60^{\circ}$, LZA $0-35^{\circ}$, RAZI $0-180^{\circ}$ ). The weak dependence of cloudUVAI on cloud altitude is not taken into account. Selection of cloudUVAI of either water or ice clouds is done using cloud top height determined by HICRU following the scheme introduced in Sect. 2.3.

In Figs. 6 and 7, we present the results from a case study where modelled cloudUVAI, both for the thick cloud and thin cloud assumption, are compared to UVAI determined from SCIAMACHY reflectance measurements. We also include a comparison to cloudUVAI calculated from spatially higher resolved MERIS cloud optical thickness. The different ways of calculating cloudUVAI from cloud parameters from either SCIAMACHY (HICRU $\mathrm{CF}_{\text {eff }}$ ) or MERIS COT are illustrated schematically in Fig. 5.
In the figure, ovals denote high spatial resolution $(1 \times$ $1 \mathrm{~km}^{2}$, MERIS resolution), whereas rectangles indicate SCIAMACHY resolution $\left(30 \times 60 \mathrm{~km}^{2}\right)$. For SCIAMACHY, the calculation of UVAI and cloudUVAI are quite straightforward, and were described above (in Sects. 3.1 and 3.2, respectively). For the MERIS data, different approaches were tested. The simplest way is to regrid the high-resolution cloud data to SCIAMACHY resolution (arrow 1 in Fig. 5), then calculating cloudUVAI from it (arrow 2 and box marked "Z"). A more accurate way is to do the calculation of MERIS cloudUVAI in two steps: first, from a LUT similar to the ones described above, reflectances at the UVAI wavelengths of 335.5 and $376.5 \mathrm{~nm}$ were determined from MERIS COT (arrow 3), assuming that clouds homogeneously cover MERIS pixels with non-zero COT (thin cloud assumption). Subsequently, these reflectances were converted to UVAI values by passing them to our standard UVAI algorithm (described in Sect. 3; arrow 6 in Fig. 5). Alternatively, we gridded the obtained MERIS-resolution cloud reflectances to the much coarser SCIAMACHY resolution (arrow 4) and subsequently converted these reflectances to UVAI (arrow 5). The reason for this two-step approach is that the boxes marked "G" and "X" in Fig. 5 are not equivalent: since UVAI depend non-linearly on the input reflectances, UVAI cannot simply be averaged over two (or more) MERIS pixels. Instead, the (modelled) UV reflectances need to be averaged, and the UVAI should be determined from the resulting reflectances. It was verified that the direct approach (where cloudUVAI is directly read from the LUT) and indirect approach (via cloud reflectances) are equivalent by comparing 

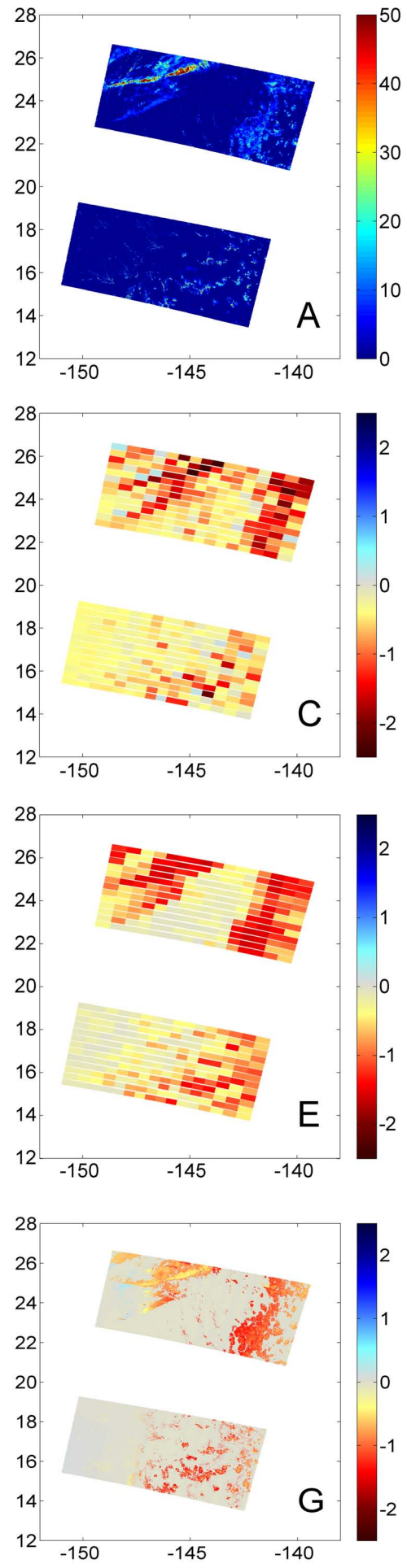
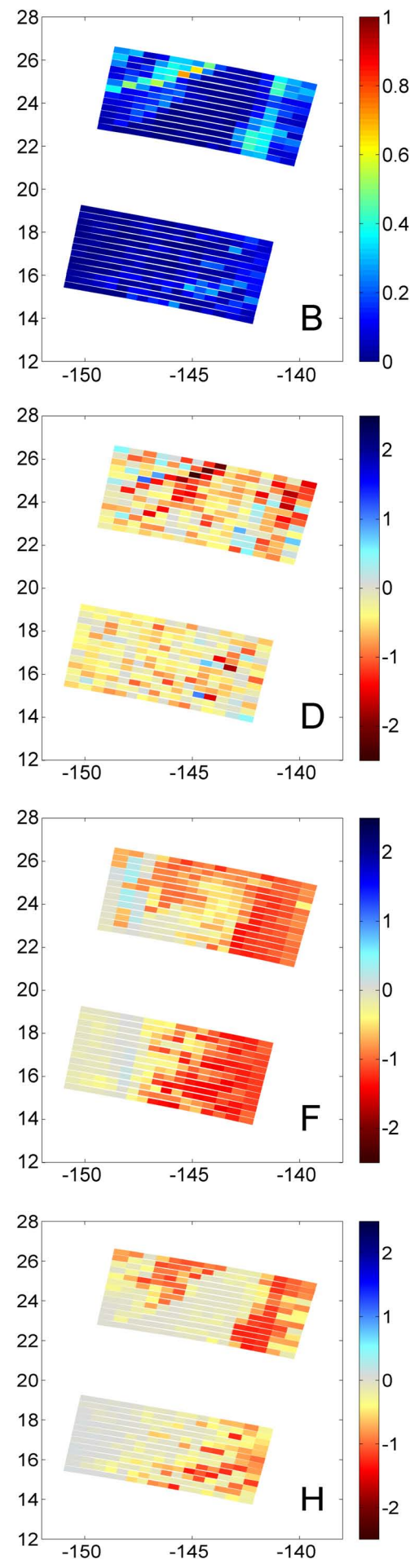

Fig. 6. Case study of cloudUVAI for SCIAMACHY states 8 and 9 in orbit 15069 (15 January 2005). Panel (A), MERIS cloud optical thickness; (B), HICRU effective cloud fraction; (C), SCIAMACHY UV Aerosol Index (LER algorithm); (D), SCIAMACHY UV Aerosol Index (MLER algorithm); (E), cloudUVAI calculated from HICRU $\mathrm{CF}_{\text {eff }}$ (for thick clouds); (F), cloudUVAI calculated from HICRU CF eff (for thin clouds); (G), cloudUVAI calculated from MERIS COT (for thin clouds) at MERIS resolution; (H), cloudUVAI calculated from MERIS COT (for thin clouds) at SCIAMACHY resolution (for details, see text). 

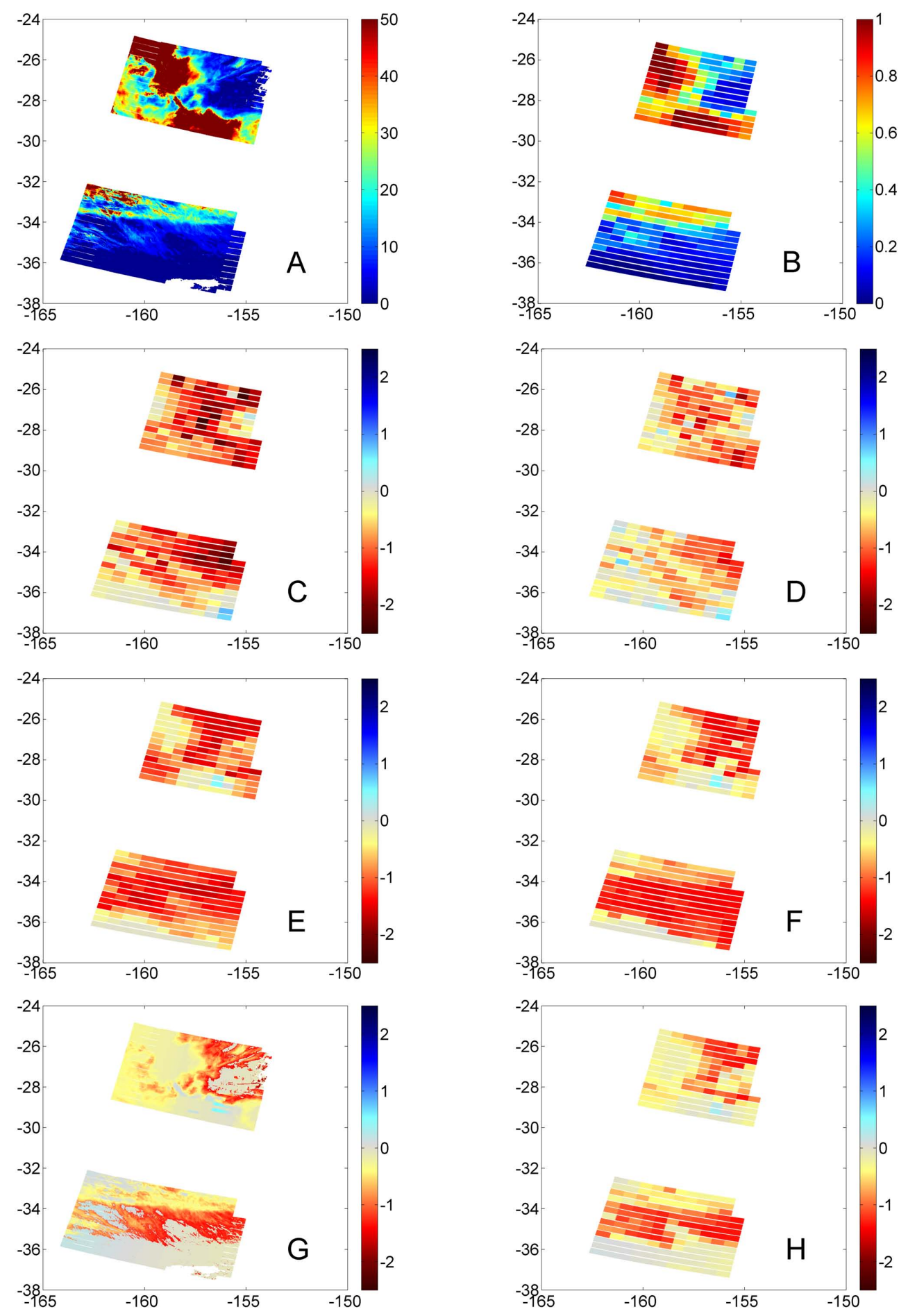

Fig. 7. Case study of cloudUVAI for SCIAMACHY states 15 and 16 in orbit 15069 (16 January 2005). Pixels with sun glint risk were discarded from the MERIS and SCIAMACHY datasets. See the caption of Fig. 6 and the text for details. 
the data marked "F" in Fig. 5 with cloudUVAI determined directly from MERIS COT (box marked “Z”).

\section{Results: cloudUVAI}

\subsection{Case studies: cloudUVAI from MERIS and SCIAMACHY cloud parameters}

For our case studies we selected two scenes from orbit 15069 of ENVISAT, performed on 16 January 2005. Both are located over the Pacific Ocean, where aerosol concentrations are expected to be small. This was verified by comparison with MODIS AOT, which did not exceed 0.1 for cloud-free pixels (MODIS AOT downloaded from the LAADS website: http://ladsweb.nascom.nasa.gov/index.html). According to our model calculations, a low-lying, non-absorbing aerosol layer (e.g. sea-spray aerosols) with an AOT of 0.1 does not significantly affect UVAI $(<0.2$ units), and the presence of even a small cloud dominates the UVAI signal.

Figure 6 displays the cloud field as measured by MERIS (COT, panel A) and by SCIAMACHY ( $\mathrm{CF}_{\text {eff }}$, panel B) for SCIAMACHY states 8 and 9 (M-Factor enumeration). The selected scene contains a high, narrow cloud with high COT in the northwest, some small scattered clouds in the east of the swath, and a largely clear scene in the southeast.

Panel $C$ shows the SCIAMACHY UVAI (calculated using the LER algorithm), which displays negative UVAI values for the clouded pixels: the cloud structures can be clearly recognized. In panel D, SCIAMACHY UVAI calculated using the MLER algorithm are displayed. The effect of clouds is much reduced compared to that seen in panel C (UVAI from LER algorithm), but still some cloud structures can be observed. In panels $\mathrm{E}$ and F, cloudUVAI calculated from HICRU $\mathrm{CF}_{\text {eff }}$ are shown for the thick and thin cloud assumption, respectively. The UVAI patterns in panel $\mathrm{E}$ are very similar to those seen in panel $\mathrm{C}$, implying that the simple thick cloud model we used for the calculation of cloudUVAI is very well suited to simulate the effect of clouds on UVAI. In contrast, the cloudUVAI calculated with the thin cloud assumption (panel F) are in much less agreement with observations. Upon more close inspection of panels C, E, and F, it is seen that the magnitude of the modelled cloudUVAI does not agree with the measured values: measured UVAI reaches much lower values $(<-2)$ than modelled with either the thick or thin cloud assumption $(-1.5)$.

In panels $\mathrm{G}$ and $\mathrm{H}$, cloudUVAI calculated from MERIS COT are shown at MERIS and at SCIAMACHY resolution, respectively. For panel H, the cloud reflectances calculated from MERIS COT were averaged to SCIAMACHY resolution, after which the UVAI were determined (see Sect. 3.4 and Fig. 5), whereas for panel G, UVAI were determined from cloud reflectances for each MERIS pixel. The viewing angle dependence of cloudUVAI (see Sect. 3.3) can most clearly be seen in panel $\mathrm{G}$ as a gradual decrease in UVAI to- wards the west of the swath and the appearance of the cloud bow at a scattering angle of about $140^{\circ}$. The spatial agreement between measured UVAI and cloudUVAI from MERIS COT is even better than for cloudUVAI from low-resolution cloud data, as seen upon comparison of panels $\mathrm{C}$ and $\mathrm{H}$. As already observed for panels $\mathrm{E}$ and $\mathrm{F}$, however, the magnitude of observed UVAI (panel C) and modelled cloudUVAI (panels E-H) do not agree well. The reason for this discrepancy is not clear, but we speculate that remaining errors in SCIAMACHY's calibration may be the cause. Another possibility is that the clouds are not modelled accurately enough. These issues will be discussed further in Sect. 6 .

The cloud field in states 15 and 16 of the same orbit as shown in Fig. 6 was quite different (Fig. 7a and b): a large part of the pixels was covered by a thick, high cloud. Several pixels in these states were flagged as having "sun-glint risk" and were discarded from both the SCIAMACHY and MERIS datasets. SCIAMACHY detected deeply negative UVAI (high SCI) for most of the scene, as shown in panel C. As observed before, the effect of clouds on MLER UVAI is smaller, but not negligible, as seen in panel D. The cloud structure is very similar to that seen in panel C for LER UVAI, but the magnitude of UVAI is smaller for the MLER UVAI.

In this case, the spatial patterns of cloudUVAI calculated from HICRU parameters using the thick cloud and the thin cloud assumption are both in reasonable agreement with the measured (LER) UVAI, as seen when comparing panel C with panels E and F. Using higher-resolution MERIS COT as input for the cloudUVAI calculations improves the spatial correspondence, although, as noted for states 8 and 9 , the measured UVAI values are significantly smaller than the modelled cloudUVAI.

In both of the case studies presented above, the best agreement between measured UVAI and modelled cloudUVAI was found when cloudUVAI were calculated from highresolution MERIS COT. Unfortunately, it would be computationally too expensive to apply this method to the whole SCIAMACHY dataset. For this reason, we also determined cloudUVAI using SCIAMACHY-resolution cloud parameters calculated from MERIS COT (arrows 1 and 2 and box marked " $Z$ " in Fig. 5). The results were very similar to those displayed in panels $\mathrm{H}$ of Figs. 6 and 7. This finding implies that the exact structure of the cloud is not of much importance to the cloudUVAI and that the description of clouds by $\mathrm{COT}$ and $\mathrm{CF}_{\text {geom }}$ at SCIAMACHY resolution is sufficient for our purpose.

\subsection{Dependence of cloudUVAI on $\mathrm{CF}_{\text {eff }}$}

We have studied daily averaged values of UVAI from SCIAMACHY and cloudUVAI calculated from HICRU cloud parameters over a remote ocean region, where the concentration of aerosols is small (as noted in the previous section). The region, at $20-40^{\circ} \mathrm{S}$ and $100-180^{\circ} \mathrm{W}$, is also not significantly 

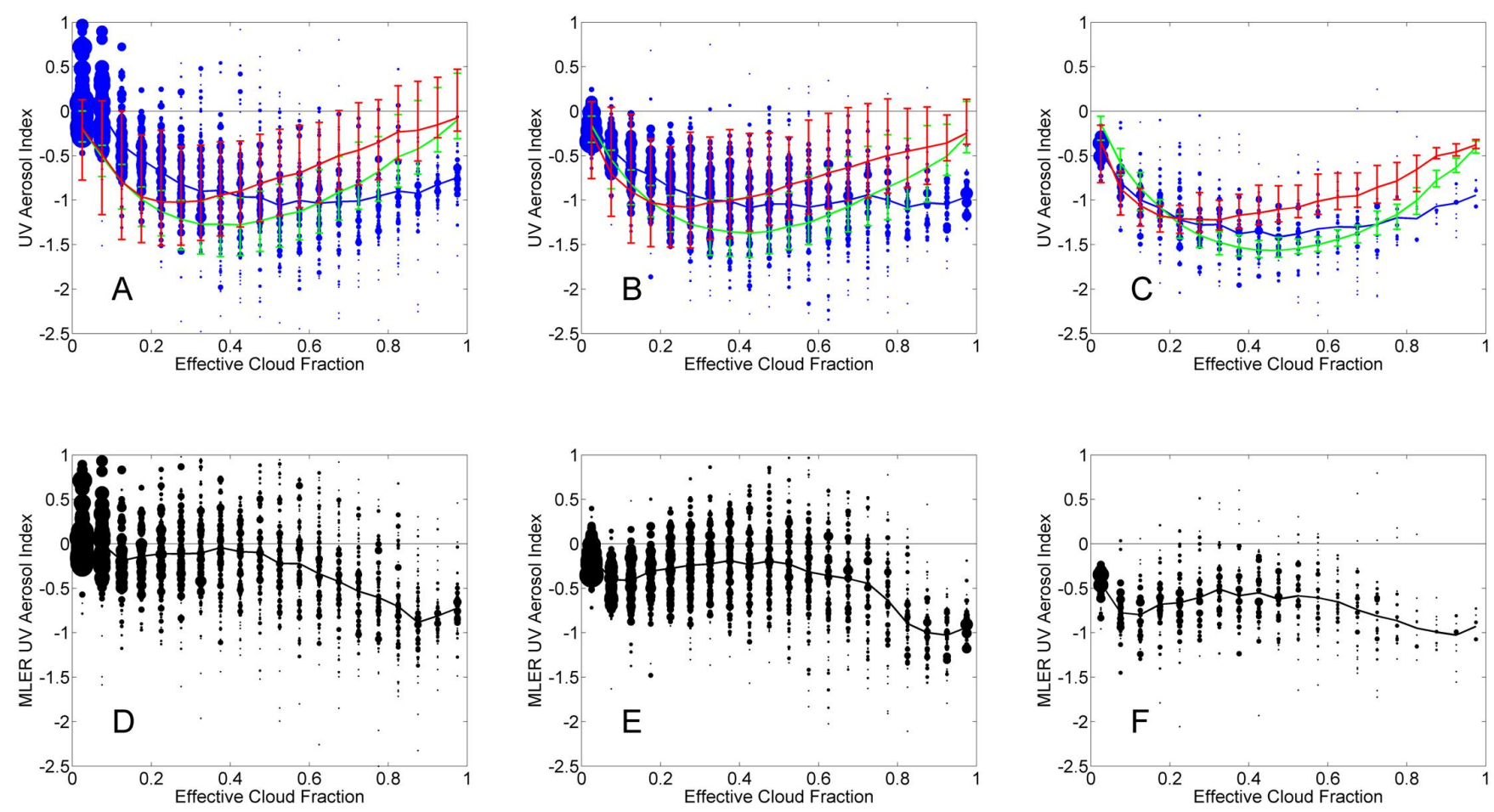

Fig. 8. Seasonally-averaged UVAI values (January-March 2005) for a region over the south-eastern Pacific Ocean $\left(20-40^{\circ} \mathrm{S}, 100-180^{\circ} \mathrm{W}\right)$. Dots indicate daily mean values, with the size of the point representing the number of data points included in the mean; lines connect monthly mean values. Data are given for three SZA ranges: $30-40^{\circ}$ (A and D), 40-50 (B and E), and 50-60 (C and F). Upper panels (A-C): blue, measured UVAI (LER algorithm); green, UVAI calculated for thick Henyey-Greenstein clouds; red, UVAI calculated for thin Henyey-Greenstein clouds. Error bars on the cloudUVAI means represent the spread of the values (i.e. the maximum and minimum daily averaged cloudUVAI). Lower panels (D-F): measured UVAI calculated using the MLER algorithm.

affected by ocean colour. The results were binned by SZA, viewing geometry, and $\mathrm{CF}_{\text {eff }}$, and subsequently averaged by day or by season. Pixels in sun glint geometry were discarded.

Figure 8 shows the average UVAI obtained for the period January-March 2005. Pixels in near-nadir geometry $\left(\right.$ LZA $\left.<10^{\circ}\right)$ are divided into three SZA bins: $30-40^{\circ}$ (panels $A$ and $D), 40-50^{\circ}$ (B and $\mathrm{E}$ ), and $50-60^{\circ}$ (C and F). In the upper panels $(\mathrm{A}-\mathrm{C})$, measured UVAI data are shown in blue with dots representing daily averages and the size of the dot indicating the number of observations; lines connect the seasonal averages. The cloudUVAI calculated with the thick cloud assumption are depicted in green and cloudUVAI calculated with the thin cloud assumption in red. Error bars on the modelled cloudUVAI indicate the spread of the data (i.e. the maximum and minimum daily averaged cloudUVAI). The lower panels (D-F) show daily and seasonally averaged UVAI calculated using the MLER algorithm.

In Fig. 8, it can be seen that the dependence of the seasonally averaged measured UVAI on $\mathrm{CF}_{\text {eff }}$ (blue) is in good agreement with the modelled cloudUVAI dependence (compare also Fig. 1): the shape of the measured UVAI dependence on $\mathrm{CF}_{\text {eff }}$ is quite well described by the model calcula- tions. There is, however, a disagreement for $\mathrm{CF}_{\text {eff }}>0.8$, and the variability in daily averaged UVAI is also not completely reproduced by the model (indicated by the error bars on the green and red cloudUVAI lines). It is not clear what the reason for these discrepancies is, although we suspect calibration errors and imperfect polarisation correction of SCIAMACHY reflectances to be a factor, as well as the inaccurate description of clouds in our radiative transfer model calculations (e.g. the assumption that clouds can be described as plane-parallel layers). The influence of ice clouds was tested by filtering the data shown in Fig. 8 to remove clouds with cloud top altitudes above $5 \mathrm{~km}$, but this did not significantly influence the results (not shown). These findings will be discussed in further detail in Sect. 6 and in the supplement to this paper.

Panels D-F in Fig. 8 show that the MLER UVAI algorithm accounts quite well for the effects of clouds for $\mathrm{CF}_{\text {eff }}<0.5$, in particular when SZA is small. Yet, a similarly large spread in MLER UVAI is found as for LER UVAI (compare panels A-C with panels D-F) and MLER UVAI at $\mathrm{CF}_{\text {eff }}>0.7$ also deviate significantly from 0 . 

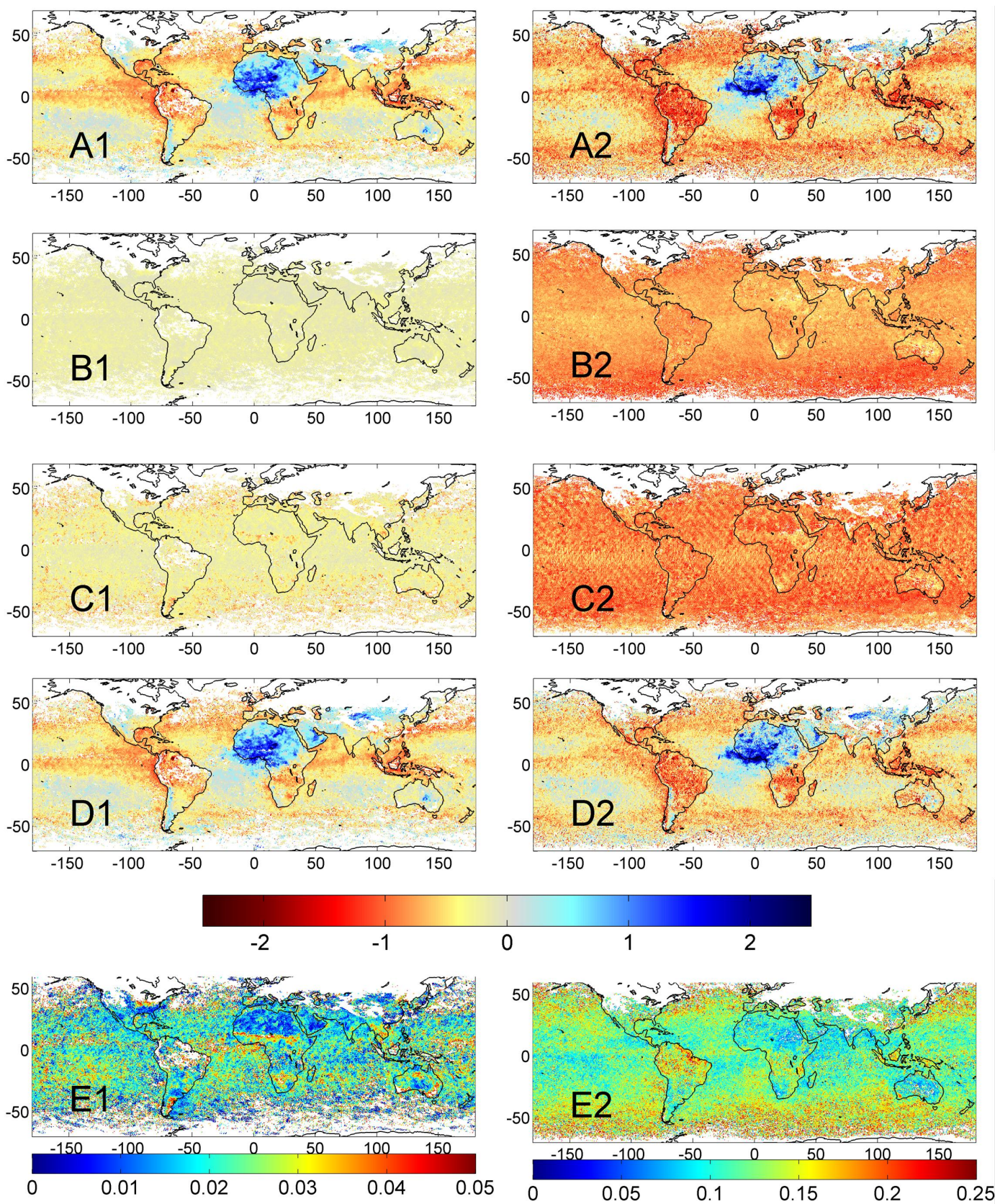

Fig. 9. Seasonally averaged measured UVAI, modelled cloudUVAI, and measured cloud fraction for January-March 2005. The data were filtered by effective cloud fraction: left column, $\mathrm{CF}_{\text {eff }}<0.05$; right column, $0.05<\mathrm{CF}_{\mathrm{eff}}<0.25$. The panels show, from top to bottom: (A) SCIAMACHY (LER) UVAI, (B) modelled cloudUVAI (for thick clouds), (C) modelled cloudUVAI (for thin clouds), (D) SCIAMACHY (MLER) UVAI, (E) HICRU $\mathrm{CF}_{\text {eff }}$ with varying colour scale. See the text for details.

\subsection{Global maps of cloudUVAI}

In Figs. 9 and 10, we present UVAI results for seasonal averages over the months January-March 2005, sorted by HICRU effective cloud fraction: the left column of Fig. 9 contains only scenes with $\mathrm{CF}_{\text {eff }}<0.05$; the right column has $\mathrm{CF}_{\text {eff }}$ between 0.05 and 0.25 ; the left and right columns of Fig. 10 contain scenes with $\mathrm{CF}_{\text {eff }} 0.25-0.50$ and $\mathrm{CF}_{\text {eff }}$
$0.50-1.0$, respectively. The rows contain (from top to bottom): SCIAMACHY average UVAI, calculated using the LER algorithm (A), cloudUVAI calculated from HICRU $\mathrm{CF}_{\text {eff }}$ for thick clouds (B) and thin clouds (C), SCIAMACHY average UVAI, calculated using the MLER algorithm (D), and average HICRU $\mathrm{CF}_{\text {eff }}$ (E). Pixels in sun-glint geometry were excluded, as were pixels influenced by snow or ice (regardless of effective cloud fraction). 

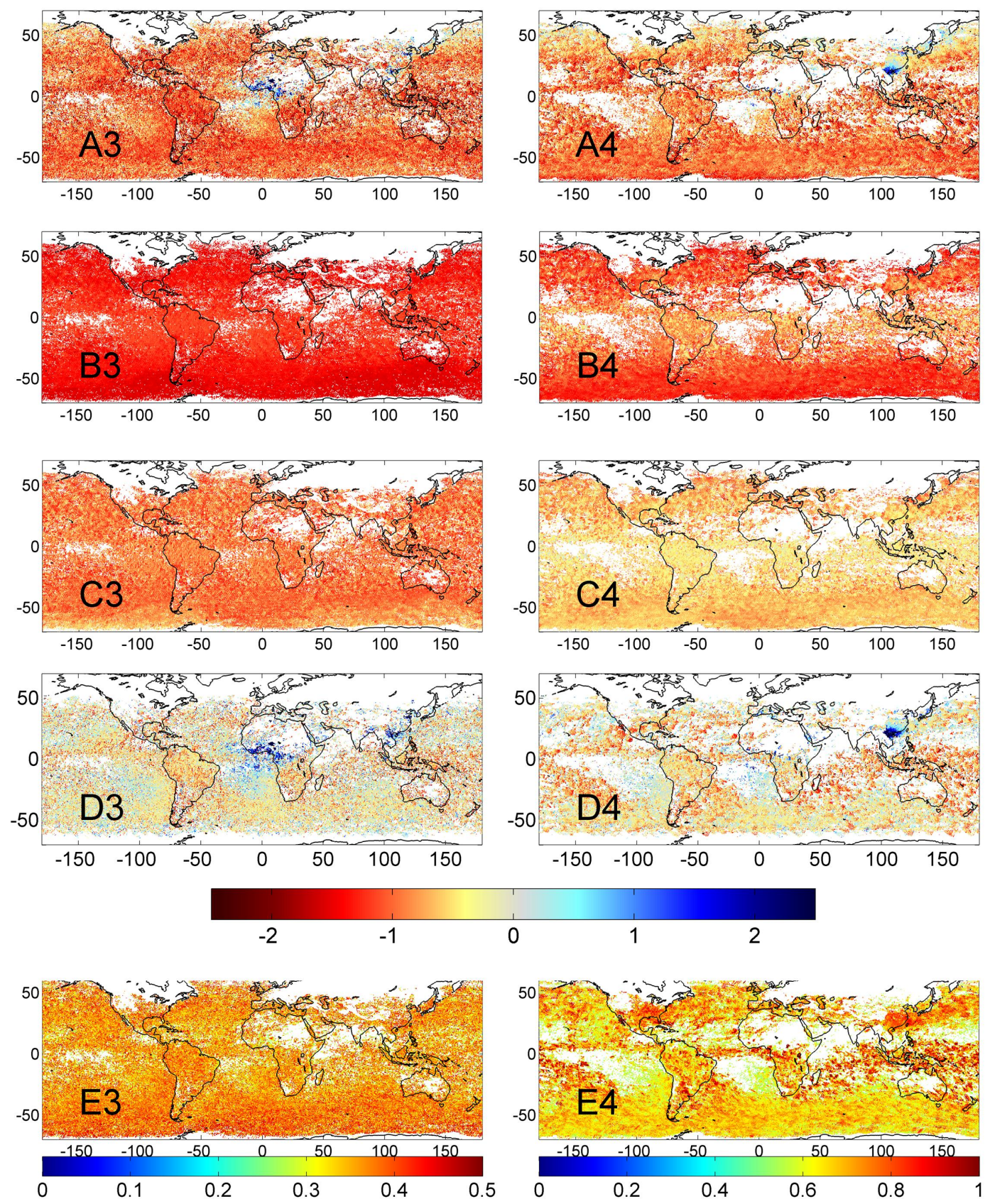

Fig. 10. Seasonally averaged measured and calculated UVAI and cloud parameters for January-March 2005. See the caption of Fig. 9 and the text for details. The data were filtered by effective cloud fraction: left column, $0.25<\mathrm{CF}_{\text {eff }}<0.5$; right column, $0.5<\mathrm{CF}_{\text {eff }}<1$.

The most prominent UVAI signals seen in panels A of Figs. 9-10 are observed over the continents, and are almost exclusively UV-absorbing aerosols, such as mineral dust (observed over the Sahara, the Arabian Peninsula, and the Taklimakan Desert) and smoke (over the Sahel region and Southeast Asia). Scattering aerosols are observed in Figs. 9 and 10 over Central Africa, as indicated by negative UVAI (non-zero $\mathrm{SCI}$ ). When comparing panels A1 and A2 in Fig. 9, the effect of clouds is immediately recognized: most of the oceans have UVAI of approximately -1 in $\mathrm{A} 2$ (where $\mathrm{CF}_{\text {eff }}$ is between 0.05 and 0.25 ), whereas in A1, UVAI in most ocean regions is near zero. This is mainly due to the UVAI from the (unpolluted) clouds themselves (cloudUVAI, effect 3 in Sect. 1). The extended ocean patches in panel A1 where UVAI remains between -1 and -0.5 are recognized as regions with enhanced chlorophyll absorption by comparing with monthly averaged MODIS ocean colour maps (obtained from: http://oceancolor.gsfc.nasa.gov/). The bright red spot 
in Venezuela is located at the Guiana Highlands, is most probably an artefact of the UVAI algorithm's sensitivity to altitude gradients (see Penning de Vries et al., 2009), and may be ignored.

The effect of clouds in panel A1 is small and rather homogeneous, as seen in the small cloudUVAI calculated for thick and thin clouds in panels B1 and C1, respectively. For such small $\mathrm{CF}_{\text {eff }}$ the scene reflectivity does not exceed that of a scene modelled with surface albedo 0.15 , therefore the LER and MLER algorithms yield identical UVAI (compare panels $\mathrm{A} 1$ and D1). In panel E1, the average $\mathrm{CF}_{\text {eff }}$ is shown.

Panels A2 and D2 of Fig. 9 show similar aerosol patterns as panels A1 and D1. Some differences can be observed, in particular in the Sahel biomass burning region, where UVAI has increased, indicating that absorbing aerosols are present in pixels contaminated by significant amounts of clouds. Also, the large plume of absorbing aerosols that is transported south-westward from Northern Africa to South America is more pronounced in panels A2 and D2 than in A1 and D1. These might be aerosols over or near clouds, but it may also be the result of HICRU's misclassification of mineral dust plumes as clouds. The magnitude of modelled cloudUVAI is very similar to the measured (LER) UVAI, although the spatial pattern is not exactly reproduced (compare panels B2 and C2 with A2). The MLER UVAI algorithm suffers less from cloud influences (panel D2), although a decrease in UVAI (increase in SCI) is clearly seen at higher latitudes.

Panels A3 and A4 in Fig. 10 are dominated by the cloud signal, as can be seen by comparison with the respective panels B and C. Yet, a significant positive UVAI is observed over the biomass-burning regions: smoke from the Sahel region is seen in panels A3 and D3, whereas smoke from agricultural fires in Southeast Asia is prominent in the corresponding panels on the right (A4 and D4). Smoke aerosols in Southeast Asia appear to be generally associated with effective cloud fractions larger than 0.5. Applying a cloud filter such as the one used to obtain panel A1 or A2 of Fig. 9 thus causes the loss of nearly all pixels with smoke aerosols in this region. This needs to be kept in mind when instruments with large footprints, such as SCIAMACHY, are used for aerosol or trace gas retrieval.

Comparison of panels A, B, and C of Fig. 10 shows that cloudUVAI determined using the thick cloud assumption are in better agreement with the measured (LER) UVAI than cloudUVAI from the thin cloud assumption, in particular for $\mathrm{CF}_{\text {eff }}$ between 0.5 and 1.0. This finding implies that, at least for $\mathrm{CF}_{\text {eff }}>0.5$, thick, broken clouds occur more frequently than thin clouds that cover the whole SCIAMACHY pixel. The MLER UVAI algorithm is, again, much less influenced by clouds than the LER algorithm (panels D and A, respectively). The effects of clouds become more obvious for $\mathrm{CF}_{\text {eff }}>0.5$, especially in regions where the largest average $\mathrm{CF}_{\text {eff }}$ are found (which can be identified in panel $\mathrm{E}$ ). At such large $\mathrm{CF}_{\text {eff }}$ only little signal from aerosols remains -
Table 1. The range of aerosol scenarios investigated for the cloud correction.

\begin{tabular}{llc}
\hline Aerosol parameter & Range & $\begin{array}{c}\text { Number } \\
\text { of values }\end{array}$ \\
\hline Asymmetry parameter, $g$ & $0.6,0.7$ & 2 \\
AOT (at 376.5 nm) & $0,0.5,1,1.5,2$ & 5 \\
Extinction Ångström exponent & $0,1,1.5,2$ & 4 \\
SSA & $0.8,0.9,0.95,1$ & 4 \\
Plume centre altitude $(\mathrm{km})$ & $1,3,5,7$ & 4 \\
\hline
\end{tabular}

apart from the biomass burning aerosols in Southeast Asia, where smoke layers regularly exist above clouds.

\section{Cloud correction of UVAI}

In this section, we introduce a first approach to a procedure to correct UVAI for the effect of clouds, rather than filtering out cloudy pixels. The simplest approach to such a cloud correction is to subtract cloudUVAI, calculated from measured $\mathrm{CF}_{\text {eff }}$, from measured UVAI. This procedure is useful for removing the effects of clouds from clean (aerosol-free) scenes, but cannot be applied to scenes strongly polluted by aerosols because the effects of clouds and aerosols on UVAI are not independent of each other. Instead, the total UVAI of a mixed cloud-and-aerosol scene depends on cloud properties as well as aerosol properties (i.e. on the UVAI of the same aerosol scene in absence of clouds), and can be described by a function $f$ of the following form:

$$
\begin{aligned}
f: & \mathrm{UVAI}_{\text {cloudy }}\left(\mathrm{CF}_{\text {eff }}, \mathrm{RCP}, \mathrm{AOT}, \mathrm{SSA}, g, \mathrm{ALH}\right) \\
& \rightarrow \mathrm{UVAI}_{\text {cloudfree }}(\mathrm{AOT}, \mathrm{SSA}, g, \mathrm{ALH})
\end{aligned}
$$

Here, $\mathrm{UVAI}_{\text {cloudy }}$ is the (measured) UVAI in the presence of clouds, which is a function of the cloud parameters $\mathrm{CF}_{\text {eff }}$ and RCP (the relative position of the cloud with respect to the aerosol layer, i.e. above or below the aerosols), and of aerosol parameters, such as AOT, SSA, $g$, their respective wavelength dependences, and ALH. UVAI cloudfree $_{\text {is the UVAI that }}$ would be detected for an identical aerosol scene in the absence of clouds. Because UVAI cloudy $_{\text {and }} \mathrm{UVAI}_{\text {cloudfree }}$ depend on SZA, LZA and RAZI, the function $f$ also depends on viewing geometry.

To find a suitable function $f$, we modelled a multitude of mixed aerosol-and-cloud scenarios, of which the aerosol parameters are listed in Table 1. Cloud parameters were kept constant: Mie clouds with $r_{\text {eff }}=16 \mu \mathrm{m}$ and COT $=50$ were assumed, extending from 0 to $1 \mathrm{~km}$ altitude (low cloud) or from 9 to $10 \mathrm{~km}$ (high cloud). Please note that the absolute altitude of the cloud has only a minor influence on the resulting UVAI, whereas the relative position - either above or below the aerosol layer - has a large impact on UVAI. The results from these calculations are shown in Fig. 11 for two cases: a cloud above an aerosol layer (panel A) and for a 

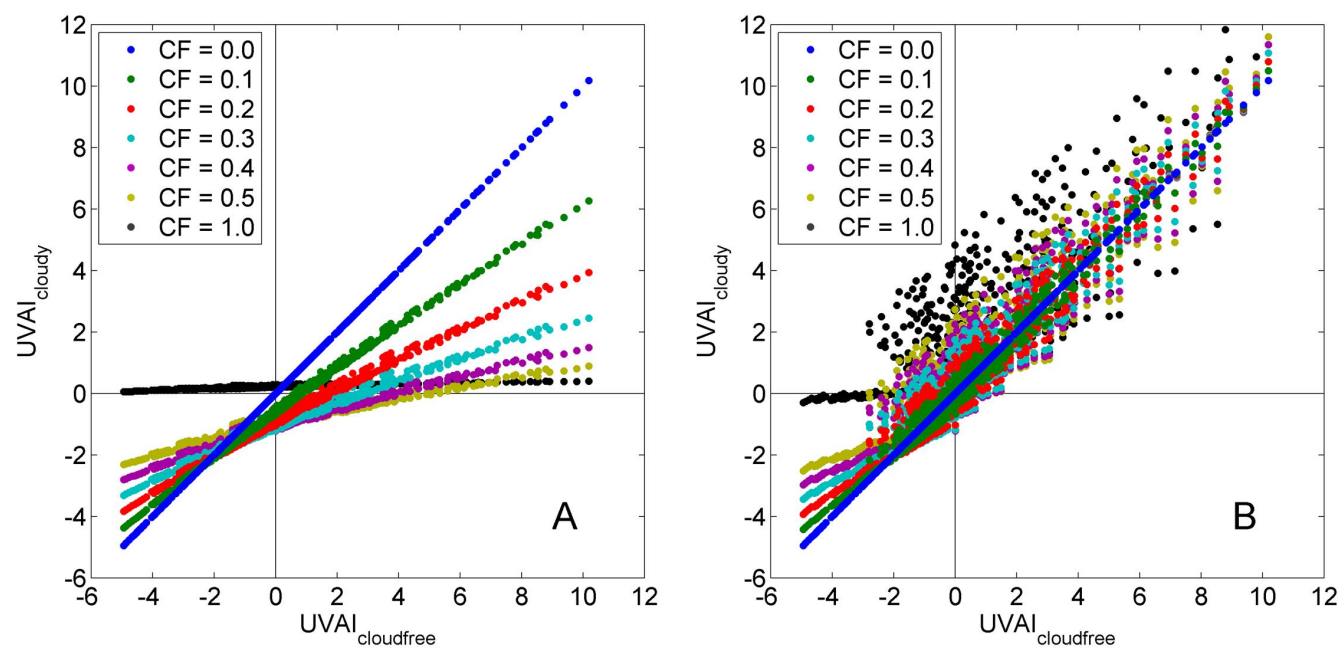

Fig. 11. Dependence of modelled UVAI from different aerosol scenarios underlying (A) or overlying (B) thick clouds for cloud fractions varying from 0 to 1 , as indicated in the legend. 640 different aerosol scenarios were modelled (see aerosol parameters in Table 1). The solar zenith angle is $20^{\circ}$ and viewing geometry is nadir.

cloud below an aerosol layer (panel B). The UVAI for each of the 640 modelled aerosol scenes with clouds is plotted against the UVAI of the corresponding scene in absence of clouds. The geometrical cloud fraction under- or overlying the aerosol layers was varied from 0 to 1 , as shown in the figure legend. By definition, a 1:1 correspondence is found for a cloud fraction of 0 . For clouds overlying an aerosol layer (high clouds, panel A), the presence of the cloud causes a near-linear decrease in UVAI of which the slope depends on the cloud fraction and viewing geometry. Such a regular dependence of $\mathrm{UVAI}_{\text {cloudy }}$ on $\mathrm{UVAI}_{\text {cloudfree }}$ can be exploited for the correction of the cloud effect on UVAI, as will be explained in more detail below.

The dependence of $\mathrm{UVAI}_{\text {cloudy }}$ on $\mathrm{UVAI}_{\text {cloudfree }}$ is less straightforward when the cloud lies below the aerosol layer (low clouds, panel B). In contrast to the high-cloud case, an increase in cloud fraction causes a change in UVAI of which the sign and magnitude depend on the specific aerosol properties. Only for purely scattering aerosols $(\mathrm{SSA}=1.0)$ (lower left quadrant of Fig. 10a and b), the effect of clouds on UVAI is nearly identical for the high-cloud and low-cloud cases. For other viewing geometries (SZA $20-60^{\circ}$, LZA 0$20^{\circ}$, RAZI $0^{\circ}$ or $180^{\circ}$ ) very similar dependences were found; changing RAZI from 0 to $40^{\circ}$, or 180 to $140^{\circ}$ (geometries that are more likely to occur for SCIAMACHY) has negligible influence on UVAI ( $<0.3$ units for extreme viewing geometry: $\mathrm{SZA}=60^{\circ}$ and $\mathrm{LZA}=30^{\circ}$ ). The model calculations were also performed for thin clouds with varying COT and similar results were obtained (not shown).

Figure 11 shows that even when a significant fraction of a satellite pixel is covered by a thick cloud, information on the (theoretical) UVAI in absence of the cloud, $\mathrm{UVAI}_{\text {cloudfree, }}$ can be obtained. Moreover, it appears that the function $f$ is smooth, and the modelled dependences of $\mathrm{UVAI}_{\text {cloudy }}$ on UVAI $_{\text {cloudfree }}$ could be well fitted with low-order polynomials. This is shown exemplarily in Fig. 12 for high clouds (panel A) and low clouds (panel B) with $\mathrm{CF}=0.2$. The data in panel A are highly linearly correlated $\left(R^{2}=0.99\right)$ and are quite well represented by the fit (plotted in red). When aerosols are located above clouds (panel B), increased scatter, already seen in Fig. 10b, leads to a decreased correlation coefficient of $R^{2}=0.92$. This is caused by the occurrence of multiple scattering between the aerosol and the cloud layer, which makes the effect of clouds on UVAI more sensitive to aerosol properties.

For clouds overlying aerosols, we use $f$ (obtained from the linear fit to the modelled data) to correct measured UVAI for the effect of clouds. However, when the cloud fraction becomes too large the shielding effect of the clouds causes the amount of aerosol information available to become very

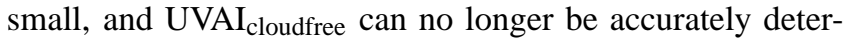
mined (seen in Fig. 10a by the decrease of the slope with increasing cloud fraction). The method is therefore restricted to scenes with small cloud fractions (roughly $\mathrm{CF}<0.5$ ). For clouds below aerosols, our cloud-correction method does not provide meaningful results due to the irregular behaviour of $\mathrm{UVAI}_{\text {cloudy }}$, which leads to slopes close to unity for all $\mathrm{CF}_{\text {eff }}$. Additional information on aerosol type or altitude is required for an accurate cloud correction of UVAI from aerosols over clouds.

The cloud correction presented in this section was applied to SCIAMACHY UVAI data from January-March 2005. For reasons outlined above, we here only show results from the cloud correction for clouds above aerosols. The results are presented in Fig. 13 for $\mathrm{CF}_{\text {eff }} 0.05-0.15$, and in Fig. 14 for $\mathrm{CF}_{\text {eff }}$ 0.15-0.25. In both figures, we show SCIAMACHY 

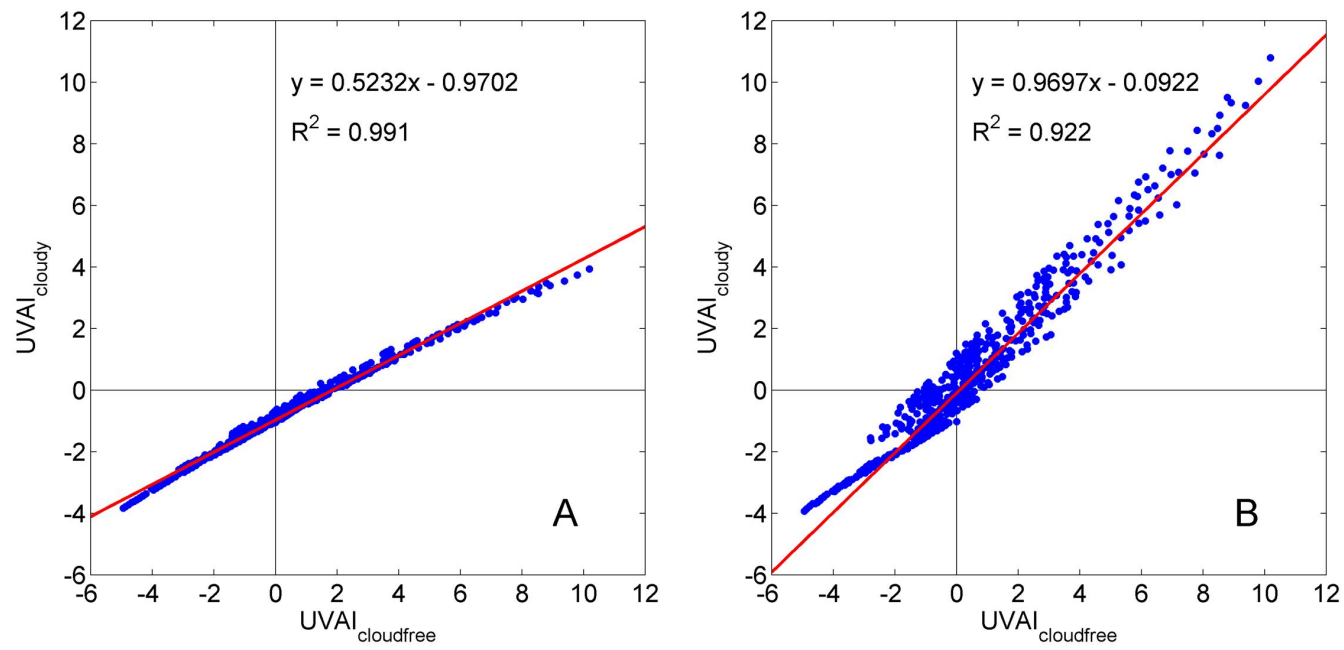

Fig. 12. Dependence of modelled UVAI from different aerosol scenarios underlying (A) or overlying (B) thick clouds. The geometrical cloud fraction is 0.2. A linear fit was applied to the data of which the coefficients are given in the plots, together with the correlation coefficient $R^{2}$. The fit to the data is shown in red.
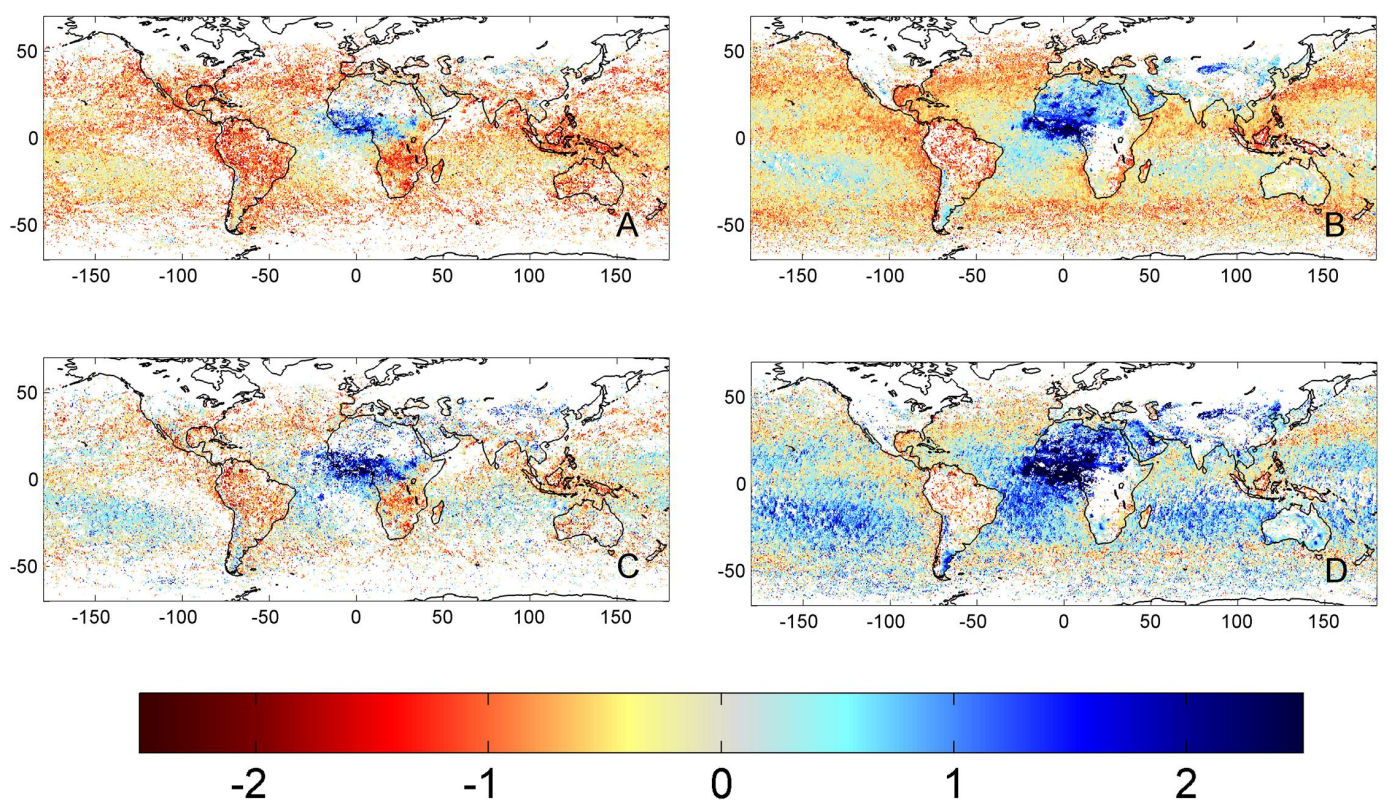

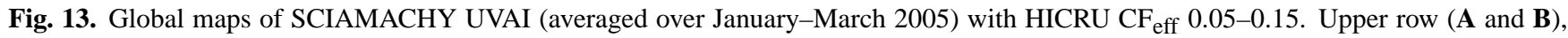
UVAI (from LER algorithm); lower row (C and D), cloud-corrected UVAI assuming that clouds are higher than the aerosols. Left panels (A and C), HICRU cloud top height $>2.5 \mathrm{~km}$; right panels (B and D), HICRU cloud top height $<2.5 \mathrm{~km}$.

UVAI in the upper panels (A and B) and UVAI cloudfree $_{\text {in the }}$ lower panels (C and D). The data were filtered by CTH: the left panels (A and C) display data with $\mathrm{CTH}>2.5 \mathrm{~km}$, the right panels (B and D) have $\mathrm{CTH}<2.5 \mathrm{~km}$.

Figures 13 and 14 both show that the average UVAI increases by application of the cloud correction, as expected when studying Figs. 11a and 12a. This is caused by the combination of negative UVAI from the cloud itself (cloudUVAI, effect 3 in Sect. 1) and the shielding of the aerosol layer by the overlying cloud (effect 1 in Sect. 1). The $\mathrm{UVAI}_{\text {cloudfree }}$ patterns in Fig. 13c appear reasonable - close to 0 over remote ocean regions, but strongly enhanced in regions where aerosols and clouds co-exist (e.g. over the Sahel). When only pixels with low clouds $(\mathrm{CTH}<2.5 \mathrm{~km})$ are considered, as in Fig. 13d, the cloud-correction algorithm appears to overcorrect the cloud effect, producing $\mathrm{UVAI}_{\text {cloudfree }}$ that are unrealistically high. 

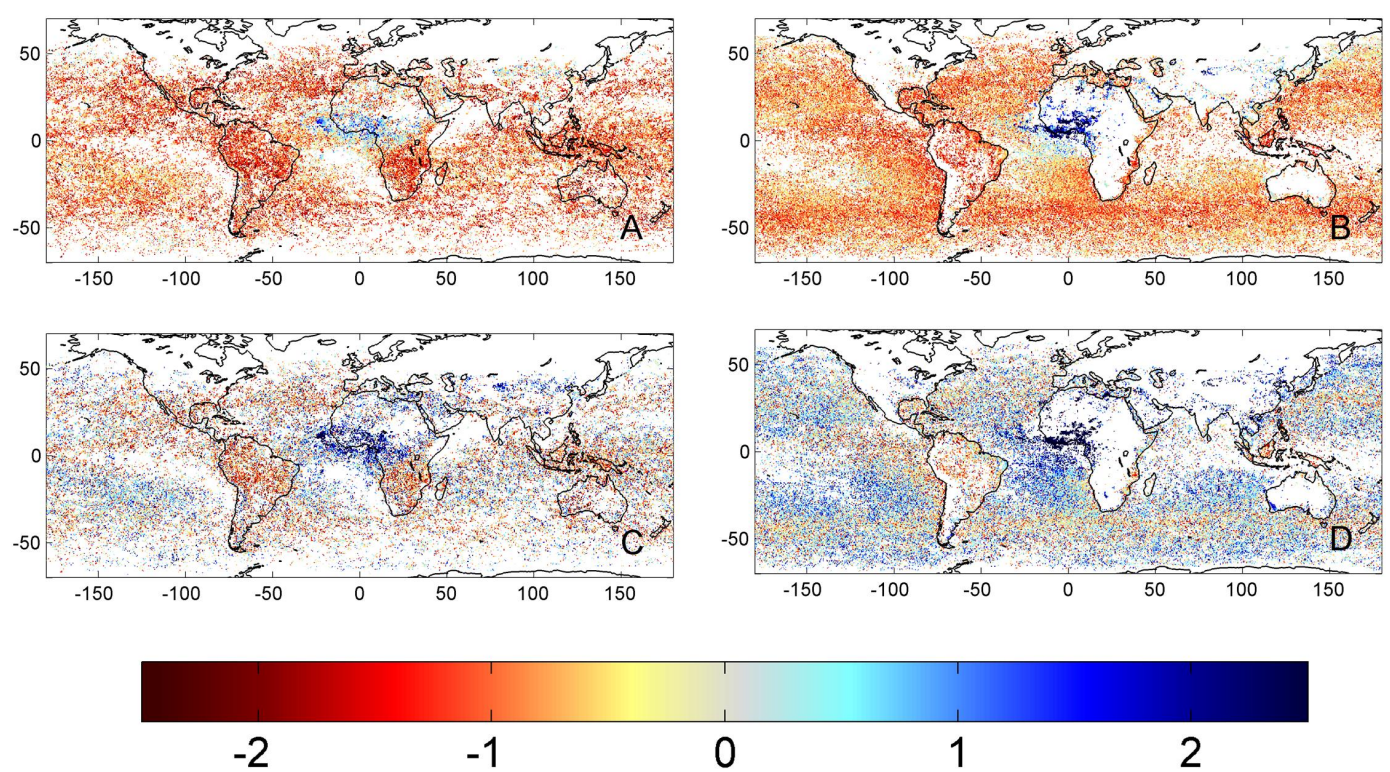

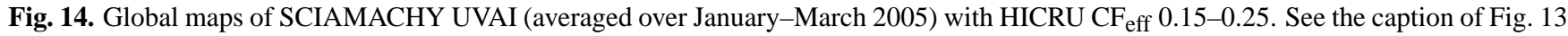
and the text for details.

Similar results are shown in Fig. 14: the average UVAI increases after cloud correction, especially for the biomass burning region in Africa, and the effects of clouds over remote ocean regions are diminished. However, more scatter can be seen in panel $\mathrm{C}$ than in Fig. $13 \mathrm{c}$ and the $\mathrm{UVAI}_{\text {cloudfree }}$ are much less reliable in this case due to the large $\mathrm{CF}_{\text {eff }}$.

\section{Discussion and conclusions}

We have investigated the effects of clouds on UVAI in a systematic way. Clouds were modelled not only as Lambertian reflectors, but also more explicitly, by using HenyeyGreenstein, Mie, or ice particle phase functions. By comparing measurements and model outcomes on different geographical scales (from local to regional and global) and time scales (from single measurements to daily and seasonal averages), we could show that even in absence of aerosols, clouds cause significant UVAI: on the order of one unit. As already noted in an earlier study (Penning de Vries et al., 2009), UVAI from clouds unpolluted by aerosols (here termed "cloudUVAI") can be quite substantial and should be taken into account, especially if spatial or time averages are being made. The presence of clouds also affects UVAI of scenes where aerosols are present, and correction of these effects is an important step towards the unambiguous detection and quantitative analysis of aerosols in the presence of clouds. Because the contributions of clouds and aerosols to UVAI are not additive, a simple subtraction of the modelled cloudUVAI is not sufficient to correct UVAI for cloud effects. Instead, both cloud properties (mainly cloud fraction) and aerosol properties (UVAI) need to be taken into account.
In this paper we introduced a first approach to such a cloudcorrection method.

\subsection{Comparison of SCIAMACHY UVAI and modelled cloudUVAI}

From the case studies presented in Sect. 4.1, we found that the spatial resolution of cloud retrieval algorithms based on SCIAMACHY measurements only does not suffice to accurately model cloudUVAI. Reasonable agreement was found for cloudUVAI calculated from HICRU $\mathrm{CF}_{\text {eff }}$, but the agreement improved when cloudUVAI were calculated from much higher resolved MERIS COT. Unfortunately, the large amount of MERIS data makes the calculation of cloudUVAI in this fashion computationally very expensive. A good compromise would be to use MERIS COT to calculate $\mathrm{CF}_{\text {geom }}$ and average COT for each SCIAMACHY pixel, and calculate cloudUVAI from them (see Fig. 5, box marked "Z"). This approach was found to yield results that were in very good agreement with cloudUVAI calculated from high-resolution MERIS cloud parameters.

In Sect. 4.2 we presented the results from a regional study where the general behaviour of UVAI as a function of effective cloud fraction observed by SCIAMACHY was found to be in good agreement with results calculated using our simple cloud model. Yet, two noteworthy differences need to be discussed in more detail here. First, the significant and systematic deviation of UVAI from 0 for clouds with $\mathrm{CF}_{\text {eff }}=1$. This deviation is present in both LER and MLER UVAI data sets, and is seen (but to a lesser extent) in the modelled cloudUVAI (Figs. 1 and 3). Second, the large spread in measured UVAI, which is observed in both LER and MLER 
UVAI data sets, but is much less for modelled cloudUVAI. In part, both the deviation of UVAI from 0 for large $\mathrm{CF}_{\text {eff }}$ and the large variation in UVAI may be explained by the occurrence of clouds with various combinations of (geometrical) cloud fraction and albedo, whereas the modelled "thick" and "thin" clouds only represent the two extreme cases. The fact that the assumptions on cloud physical parameters (a single, plane-parallel layer, simple particle size distributions, cloud phase) are not always valid may be another reason. There is also a small, cloud-height dependent contribution from the Ring effect (less than 0.5 units), as discussed in Sect. 3.3. Another explanation that cannot be ruled out currently is the influence of errors in SCIAMACHY reflectances, in particular those caused by the sensitivity of SCIAMACHY to polarisation, to which UVAI is notoriously sensitive (Tilstra et al., 2007). In the future, we will compare UVAI from other instruments (GOME-2 and OMI) to SCIAMACHY UVAI and modelled cloudUVAI to assess the impact of instrument errors. A first analysis of UVAI from GOME-2 shows results that are very similar to those found here for SCIAMACHY.

In an effort to quantify and understand the abovementioned differences we created histograms of measured UVAI and modelled cloudUVAI and studied the dependence of the difference (measured UVAI - modelled cloudUVAI) on viewing angle and cloud fraction. The details and results of this analysis can be found in the supplement to this paper. The two most important findings are that (1) the viewingangle dependence varies with cloud fraction; and (2) the agreement between measurement and model becomes better with increasing SZA. This may point to remaining inaccuracies in the cloud model (in particular in the phase function), but do not rule out instrument problems.

From the maps depicting the global influence of clouds on UVAI (Figs. 9-10) several conclusions can be drawn. First, the effects of clouds on UVAI are significant and need to be accounted for. Second, that modelled cloudUVAI UVAI from clouds unpolluted by aerosols - can reasonably reproduce these cloud effects. Comparison of panels A-C in Fig. 10 suggests that for $\mathrm{CF}_{\text {eff }}>0.5$ "thick" clouds (optically thick clouds with variable geometrical cloud fraction) occur more frequently than "thin" clouds. A third conclusion from Figs. 9-10 is that applying a cloud filter to satellite measurements with coarse spatial resolution (e.g. SCIAMACHY, GOME-2, OMI) causes the loss of potentially interesting scenes where aerosols are associated with clouds. This is most clearly seen for the biomass burning region in Southeast Asia, where absorbing aerosols are only detected when $\mathrm{CF}_{\text {eff }}>0.5$ (compare panels A of Figs. 9-10).

\subsection{LER and MLER UVAI algorithms}

The UVAI is meant to be a measure of aerosols and should, ideally, be insensitive to clouds. In this sense, the MLER UVAI algorithm clearly performs better than the LER algorithm, yielding UVAI closer to zero in most cases (most clearly seen in Fig. 8). However, even for the MLER UVAI algorithm the effect of clouds can be significant: for small cloud fractions (approximately $\mathrm{CF}_{\text {eff }}<0.1$ ) the algorithms are identical, and cloudUVAI can reach -1.2 (Fig. 3b). The algorithms also yield identical results for large clouds, and non-zero values of both LER and MLER UVAI are found for $\mathrm{CF}_{\text {eff }}=1$ (Fig. 8).

Although the MLER UVAI algorithm is less sensitive to clouds unpolluted by aerosols in many cases, as discussed above, also for the MLER algorithm the effects of aerosols and clouds on UVAI are not additive. The cloud-correction procedure described in Sect. 5 should therefore also be applied to MLER UVAI. This was not investigated in the present study.

\subsection{Cloud correction of UVAI}

Aerosol and cloud effects on UVAI are not independent, therefore modelled cloudUVAI may not be used to correct UVAI for cloud effects in scenes containing aerosols. It can, however, be used to asses whether or not measured UVAI can be solely attributed to clouds, or if the scene is additionally polluted by aerosols.

For a more quantitative correction of cloud effects on UVAI, we have developed a first, simple approach. Our cloud correction is based on the assumption, verified by extensive model calculations, that a UVAI representative of a cloudfree scene $\left(\mathrm{UVAI}_{\text {cloudfree }}\right)$ can be derived from measurements of UVAI and $\mathrm{CF}_{\text {eff. }}$. The method is currently only applicable to situations where clouds are located above an aerosol layer. When clouds are located beneath an aerosol layer multiple scattering between both layers causes the effect of clouds to strongly depend on aerosol properties, such as absorption optical depth and aerosol layer altitude.

For small and moderate cloud fractions $\left(\mathrm{CF}_{\text {eff }}<0.25\right)$, the developed cloud correction leads to more realistic UVAI (Figs. 13-14). For larger cloud fractions, the correction does not work well, mainly because the relative contribution of the aerosols to the measured reflectance decreases due to the dominating contribution from clouds. In addition, limitations of the cloud and aerosol models and errors in instrument calibration contribute to the imperfect cloud correction.

Our cloud-correction method is not mature enough to be used on a routine basis, but rather provides a starting point for the development of a more extensive and accurate cloudcorrection procedure. The method might not be accurate enough yet for use on a single-measurement basis, but instead serves to improve spatial or time-averaged UVAI data. This is in line with our view that small UVAI, and SCI in particular, be used either in conjunction with other quantities, such as AOT, or to use values averaged in time or space. In contrast to the more generally used cloud filter, applying such a cloud correction selectively removes the cloud effects without discarding signals from aerosols in (partly) clouded 
pixels, opening a door to the interesting field of aerosol-cloud interactions.

\section{Supplementary material related to this article is available online at: http://www.atmos-chem-phys.net/11/12715/2011/ acp-11-12715-2011-supplement.pdf.}

Acknowledgements. O. Torres and several anonymous reviewers are kindly thanked for comments that were very helpful in improving the manuscript. M. de Graaf, A. Kokhanovsky, J. Leitao, and especially L. Lelli are acknowledged for their help with the modelling of clouds. H. Sihler is acknowledged for critical reading of the manuscript. We are thankful for S. Dörner's help with EMAC data. IUP Bremen, A. Rozanov and V. Rozanov are kindly thanked for providing a pre-release version of SCIATRAN 3.0 (from http://www.iup.physik.uni-bremen.de/sciatran/downloads/), and for their technical support. SCIAMACHY and MERIS data were provided by ESA. The MODIS team and NASA are thanked for making their data freely available via http://ladsweb.nascom.nasa.gov/index.html. M. P. d. V. acknowledges the Max Planck Society for a research grant.

The service charges for this open access publication have been covered by the Max Planck Society.

Edited by: M. Van Roozendael

\section{References}

Ahmad, Z., Bhartia, P. K., and Krotkov, N.: Spectral properties of backscattered UV radiation in cloudy atmospheres, J. Geophys. Res., 109, D01201, doi:10.1029/2003JD003395, 2004.

Andreae, M. O. and Rosenfeld, D.: Aerosol-cloud-precipitation interactions. Part 1. The nature and sources of cloud-active aerosols, Earth Sci. Rev., 89, 13-41, 2008.

Bovensmann, H., Burrows, J. P., Buchwitz, M., Frerick, J., Noël, S., Rozanov, V. V., Chance, K. V., and Goede, A. P. H.: SCIAMACHY: Mission objectives and measurements modes, J. Atmos. Sci., 56, 127-150, 1999.

Chiapello, I., Prospero, J. M., Herman, J. R., and Hsu, N. C.: Detection of mineral dust over the North Atlantic Ocean and Africa with the Nimbus 7 TOMS, J. Geophys. Res., 104, 9277-9291, 1999.

Darmenova, K., Sokolik, I. N., and Darmenov, A.: Characterization of east Asian dust outbreaks in the spring of 2001 using ground-based and satellite data, J. Geophys. Res., 110, D02204, doi:10.1029/2004JD004842, 2005.

Davidi, A., Koren, I., and Remer, L.: Direct measurements of the effect of biomass burning over the Amazon on the atmospheric temperature profile, Atmos. Chem. Phys., 9, 8211-8221, doi:10.5194/acp-9-8211-2009, 2009.

de Graaf, M., Stammes, P., Torres, O., and Koelemeijer, R. B. A.: Absorbing Aerosol Index - Sensitivity analysis, application to GOME and comparison with TOMS, J. Geophys. Res., 110, D01202, doi:10.1029/2004JD005178, 2005.

de Graaf, M., Stammes, P., and Aben, E. A. A.: Analysis of reflectance spectra of UV-absorbing aerosol scenes mea- sured by SCIAMACHY, J. Geophys. Res., 112, D02206, doi:10.1029/2006JD007249, 2007.

Deirmendjian, D.: Electromagnetic light scattering on sperical polydispersions, Elsevier, Amsterdam, 1969.

Dirksen, R. J., Boersma, K. F., de Laat, J., Stammes, P., van der Werf, G. R., Val Martin, M., and Kelder, H. M.: An aerosol boomerang: Rapid around-the-world transport of smoke from the December 2006 Australian forest fires observed from space, J. Geophys. Res., 114, D21201, doi:10.1029/2009JD012360, 2009.

Fromm, M., Tupper, A., Rosenfeld, D., Servanckx, R., and McRae, R.: Violent pyro-convective storm devastates Australia's capital and pollutes the stratosphere, Geophys. Res. Lett., 33, L05815, doi:10.1029/2005GL025161, 2006.

Gleason, J. F., Hsu, N. C., and Torres, O.: Biomass burning smoke measured using backscattered ultraviolet radiation: SCAR-B and Brazilian smoke interannual variability, J. Geophys. Res., 103, 31969-31978, 1998.

Grainger, J. F. and Ring, J.: Anomalous Fraunhofer line profiles, Nature, 193, p. 762, doi:10.1038/193762a0, 1962.

Grzegorski, M., Wenig, M., Platt, U., Stammes, P., Fournier, N., and Wagner, T.: The Heidelberg iterative cloud retrieval utilities (HICRU) and its application to GOME data, Atmos. Chem. Phys., 6, 4461-4476, doi:10.5194/acp-6-4461-2006, 2006.

Guan, H., Esswein, R., Lopez, J., Bergstrom, R., Warnock, A., Follette-Cook, M., Fromm, M., and Iraci, L. T.: A multidecadal history of biomass burning plume heights identified using aerosol index measurements, Atmos. Chem. Phys., 10, 64616469, doi:10.5194/acp-10-6461-2010, 2010.

Hansen, J. E.: Exact and approximate solutions for multiple scattering by cloud and hazy planetary atmospheres, J. Atmos. Sci., 26, 478-487, 1969.

Henyey, L. and Greenstein, J.: Diffuse radiation in the galaxy, Astrophys. J., 93, 70-83, 1941.

Herman, J. R., Bhartia, P. K., Torres, O., Hsu, C., Seftor, C., and Celarier, E.: Global distribution of UV-absorbing aerosols from Nimbus 7/TOMS data, J. Geophys. Res., 102, 16911-16922, 1997.

Hsu, N. C., Herman, J. R., Bhartia, P. K., Seftor, C. J., Torres, O., Thompson, A. M., Gleason, J. F., Eck, T. F., and Holben, B. N.: Detection of biomass burning smoke from TOMS measurements, Geophys. Res. Lett., 23, 745-748, 1996.

Hsu, N. C., Herman, J. R., Gleason, J. F., Torres, O., and Seftor, C. J.: Satellite detection of smoke aerosols over a snow/ice surface by TOMS, Geophys. Res. Lett., 26, 1165-1168, 1999.

Hsu, N. C., Herman, J. R., and Tsay, S.-C.: Radiative Impacts from biomass burning in the presence of clouds during boreal spring in southeast Asia, Geophys. Res. Lett., 30, 1224, doi:10.1029/2002GL016485, 2003.

Hu, R.-M., Martin, R. V., and Fairlie, T. D.: Global retrieval of columnar aerosol single scattering albedo from space-based observations, J. Geophys. Res., 112, D02204, doi:10.1029/2005JD006832, 2007.

Jeong, M.-J. and Hsu, N. C.: Retrievals of aerosol single-scattering albedo and effective aerosol layer height for biomass-burning smoke: Synergy derived from “A-Train” sensors, Geophys. Res. Lett., 35, L24801, doi:10.1029/2008GL036279, 2008.

Jethva, H. and Torres, O.: Satellite-based evidence of wavelengthdependent aerosol absorption in biomass burning smoke inferred from Ozone Monitoring Instrument, Atmos. Chem. Phys., 11, 
10541-10551, doi:10.5194/acp-11-10541-2011, 2011.

Jöckel, P., Tost, H., Pozzer, A., Brühl, C., Buchholz, J., Ganzeveld, L., Hoor, P., Kerkweg, A., Lawrence, M. G., Sander, R., Steil, B., Stiller, G., Tanarhte, M., Taraborrelli, D., van Aardenne, J., and Lelieveld, J.: The atmospheric chemistry general circulation model ECHAM5/MESSy1: consistent simulation of ozone from the surface to the mesosphere, Atmos. Chem. Phys., 6, 50675104, doi:10.5194/acp-6-5067-2006, 2006.

Koelemeijer, R. B. A., Stammes, P., Hovenier, J. W., and de Haan, J. F.: A fast method for retrieval of cloud parameters using oxygen A band measurements from the Global Ozone Monitoring Experiment, J. Geophys. Res., 106, 3475-3490, 2001.

Koren, I., Vanderlei Martins, J., Remer, L. A., and Afargan, H.: Smoke invigoration versus inhibition of clouds over the Amazon, Science, 321, 946-949, 2008.

Krijger, J. M., van Weele, M., Aben, I., and Frey, R.: Technical Note: The effect of sensor resolution on the number of cloud-free observations from space, Atmos. Chem. Phys., 7, 2881-2891, doi:10.5194/acp-7-2881-2007, 2007.

Macke, A., Mueller, J., and Raschke, E.: Single Scattering Properties of Atmospheric Ice Crystals, J. Atmos. Sci., 53, 2813-2825, 1996.

Mahowald, N. M. and Dufresne, J.-L.: Sensitivity of TOMS aerosol index to boundary layer height: Implications for detection of mineral aerosol sources, Geophys. Res. Lett., 31, L03103, doi:10.1029/2003GL018865, 2004.

McPeters, R. D., Bhartia, P. K., Krueger, A. J., Herman, J. R., Wellemeyer, C. G., Seftor, C. J., Jaross, G., Torres, O., Moy, L., Labow, G., Byerly, W., Taylor, S. L., Swissler, T., and Cebula, R. P.: Earth Probe Total Ozone Mapping Spectrometer (TOMS) Data Products User's Guide, NASA Technical Publication 1998206895, 1998.

Mie, G.: Beiträge zur Optiktrüber Medien, speziell kolloidaler Metallösungen, Ann. Phys., 330, 377-455, 1908.

Penning de Vries, M. J. M., Beirle, S., and Wagner, T.: UV Aerosol Indices from SCIAMACHY: introducing the SCattering Index (SCI), Atmos. Chem. Phys., 9, 9555-9567, doi:10.5194/acp-99555-2009, 2009.

Platt, U. and Stutz, J.: Differential Optical Absorption Spectroscopy: Principles and Applications, in: Physics of Earth and Space Environment Series, edited by: Guzzi, R., Lanzerotti, L., and Platt, U., Springer, 2008.

Pöschl, U.: Atmospheric aerosols: Composition, transformation, climate and health effects, Angew. Chem. Int. Edit., 44, 75207540, 2005.

Rosenfeld, D., Lohmann, U., Raga, G. B., O’Dowd, C. D., Kulmala, M., Fuzzi, S., Reissell, A., and Andreae, M. O.: Flood or drought: How do aerosols affect precipitation, Science, 321, 1309-1313, 2008.

Rozanov, A., Rozanov, V., Buchwitz, M., Kokhanovsky, A., and Burrows, J. P.: SCIATRAN 2.0 - A new radiative transfer model for geophysical applications in the $175-2400 \mathrm{~nm}$ spectral region, Adv. Space Res., 36, 1015-1019, 2005.

Rozanov, V. V. and Kokhanovsky, A. A.: The solution of the vector radiative transfer equation using the discrete ordinates technique: selected applications, J. Atmos. Res., 79, 241-265, 2006.

Rozanov, V. V., Buchwitz, M., Eichmann, K.-U., de Beek, R., and Burrows, J. P.: SCIATRAN - A new radiative transfer model for geophysical applications in the $240-2400 \mathrm{~nm}$ spectral region: the pseudo-spherical version, Adv. Space Res., 29, 1831-1835, 2002.

Satheesh, S. K., Torres, O., Remer, L. A., Suresh Babu, S., Vinoj, V., Eck, T. F., Kleidman, R. G., and Holben, B. N.: Improved assessment of aerosol absorption using OMI-MODIS joint retrieval, J. Geophys. Res., 114, D05209, doi:10.1029/2008JD011024, 2009.

Seinfeld, J. H. and Pandis, S. N.: Atmospheric Chemistry and Physics: From air pollution to climate change, second edn., Wiley, New York, 2006.

Tilstra, L. G., de Graaf, M., Noël, S., Aben, I., and Stammes, P.: SCIAMACHY's Absorbing Aerosol Index and the consequences of instrument degradation, Proc. ACVE-3, 2007.

Torres, O., Bhartia, P. K., Herman, J. R., Ahmad, Z., and Gleason, $\mathrm{J}$.: Derivation of aerosol properties from satellite measurements of backscattered ultraviolet radiation: Theoretical basis, J. Geophys. Res., 103, 17099-17110, 1998.

Torres, O., Bhartia, P. K., Herman, J. R., Sinyuk, A., Ginoux, P., and Holben, B.: A long-term record of aerosol optical depth from TOMS observations and comparison to AERONET measurements, J. Atmos. Sci., 59, 398-413, 2002.

Torres, O., Bhartia, P. K., Sinyuk, A., Welton, E. J., and Holben, B.: Total Ozone Mapping Spectrometer measurements of aerosol absorption from space: Comparison to SAFARI 2000 ground-based observations, J. Geophys. Res., 110, D10S18, doi:10.1029/2004JD004611, 2005.

Torres, O., Tanskanen, A., Veihelmann, B., Ahn, C., Braak, R., Bhartia, P. K., Veefkind, P., and Levelt, P.: Aerosols and surface UV products from Ozone Monitoring Instrument observations: An overview, J. Geophys. Res., 112, D24S47, doi:10.1029/2007JD008809, 2007.

Torres, O., Jethva, H., and Bhartia, P. K.: Retrieval of Aerosol Optical Depth above Clouds from OMI Observations: Sensitivity Analysis and Case Studies, J. Atmos. Sci, in press, 2011.

van de Hulst, H. C.: Light scattering by small particles, New York, John Wiley and Sons, 1957.

Veihelmann, B., Levelt, P. F., Stammes, P., and Veefkind, J. P.: Simulation study of the aerosol information content in OMI spectral reflectance measurements, Atmos. Chem. Phys., 7, 3115-3127, doi:10.5194/acp-7-3115-2007, 2007.

Wagner, T., Beirle, S., Deutschmann, T., Eigemeier, E., Frankenberg, C., Grzegorski, M., Liu, C., Marbach, T., Platt, U., and Penning de Vries, M.: Monitoring of atmospheric trace gases, clouds, aerosols and surface properties from UV/vis/NIR satellite instruments, J. Opt. A-Pure Appl. Op., 10, 104019, doi:10.1088/1464-4258/10/10/104019, 2008.

Wang, P., Stammes, P., van der A, R., Pinardi, G., and van Roozendael, M.: FRESCO+: an improved $\mathrm{O}_{2}$ A-band cloud retrieval algorithm for tropospheric trace gas retrievals, Atmos. Chem. Phys., 8, 6565-6576, doi:10.5194/acp-8-6565-2008, 2008.

Wendisch, M., Pilewskie, P., Pommier, J., Howard, S., Yang, P., Heymsfield, A. J., Schmitt, C. G., Baumgardner, D., and Mayer, B.: Impact of cirrus crystal shape on solar spectral irradiance: A case study for subtropical cirrus, J. Geophys. Res., 110, D03202, doi:10.1029/2004JD005294, 2005. 